\title{
The Price of an Uncertain Promise: Fair Value Accounting and the Shaping of Bank Counterparty Risk Valuation Practices
}

\author{
Taylor Spears \\ 11 March 2018
}

Author's Address:

School of Social and Political Science

University of Edinburgh

Chrystal Macmillan Building

15a George Square

Edinburgh

EH8 9LD

United Kingdom

taylor.spears@ed.ac.uk 


\title{
The Price of an Uncertain Promise: Fair Value Accounting and the Shaping of Bank Counterparty Risk Valuation Practices
}

\begin{abstract}
How did the adoption of fair value accounting by the FASB shape the financial modelling practices used by market practitioners? Drawing on documentary sources, ethnographic fieldwork, and 52 interviews with financial economists and market participants, this article addresses this question by tracing the development and adoption of the mathematical models and associated infrastructures that derivatives 'dealer' banks use to assign value to the counterparty risk embedded in the 'over-the-counter' derivatives contracts they trade. Rather than reflecting a pre-existing consensus on the part of financial market participants in favour of valuation practices drawn from financial economics, this article suggests that the switch to fair value actively shaped the financial modelling and risk management practices used by dealers to value and manage this risk. While a number of material and institutional factors shaped the adoption of these practices, the switch to fair value ultimately 'tipped the balance' in favor of a particular set of practices that were preferred by a minority of investment banks. In explaining the development and adoption of banks' counterparty risk modelling practices, this paper develops a hybrid theoretical approach that combines organisational institutionalism's focus on meso-level field dynamics and the social studies of finance's focus on materiality.
\end{abstract}

\section{Keywords}

Fair value, financial modelling, social studies of finance, institutional logics, materiality, valuation practices. 


\section{Introduction}

In recent years, a growing body of accounting research has emerged that aims to explain the rapid adoption of 'fair value' accounting practices among accounting standard-setting authorities, despite widespread concerns about the reliability of these techniques compared to more traditional 'historical cost' valuation practices. Of particular interest has been the cultural and intellectual influence of the discipline of financial economics in helping to effect this change (c.f. Power 2010; Morley 2014). Existing work has shown that the problem of accounting for derivatives - whose valuation is difficult to reconcile with a historical-cost methodology of value measurement - provided an important opportunity for proponents of fair value to position it as a necessary alternative. These advocates were also able to point to a growing consensus among financial market participants in favor of valuation models drawn from financial economics - particularly the Black-Scholes model for pricing equity options and its intellectual descendants - as evidence of the appropriateness of fair value techniques.

While financial economics and the popularity of its methods did play an important role in effecting the adoption of fair value accounting principles, what has attracted less attention is the converse question, i.e. the effects of the switch to fair value on the financial modelling and valuation practices used by market participants. This is an important question given that both proponents and critics of fair value accounting tend to assume that the switch to fair value entailed what one might call the 'financialization' of accounting: the incorporation, within accounting standards, of a pre-existing consensus among market participants in favor of techniques drawn from financial economics, particularly in the derivatives markets, rather than fair value itself influencing the adoption of such techniques. Unfortunately, there has been relatively little focused empirical work on the development and adoption of these financial modelling practices and how their adoption coincided with emergence of fair value accounting. Within the accounting literature, much of the existing work on fair value has focused primarily on the activities of standards setters at the core of accounting, and much less on the financial models and infrastructures along its 'margins' (Miller 1998).

To address this question, this paper examines the development, adoption, and institutionalization of the financial modelling practices and infrastructures used by derivatives 'dealer' banks to calculate a specific set of fair value measurements: the valuation of the counterparty risk associated with derivatives that are traded on an 'over-the-counter' (OTC) basis. (Counterparty risk refers to the risk that a financial market participant may go bankrupt and be unable to meet its derivatives-related liabilities.) Current financial accounting standards promulgated by both the US-based Financial Accounting Standards Board (FASB) and the International Accounting Standards Board (IASB) require financial institutions to reflect the fair value of counterparty risk in their financial statements. SFAS 157, for instance, requires that fair value measurements include a "risk premium reflecting the amount market participants would demand because 
of the risk (uncertainty) in the cashflows" (Financial Accounting Standards Board 2006, B5) and further specifies that reporting entities "consider the effect of its credit risk (credit standing) on the fair value of the liability in all periods in which the liability is measured at fair value" (Financial Accounting Standards Board 2006, A31). These adjustments played a prominent role in the 2008 financial crisis: As the Basel Committee on Banking Supervision noted in 2009, nearly two-thirds of banks' counterparty-related losses during the crisis arose not from actual defaults, but from fair value losses associated with the changing value of counterparty risk (Basel Committee on Banking Supervision 2009). When the dust had settled, these mark-to-market losses constituted the third largest category of losses that banks suffered during the crisis (UK Financial Services Authority 2010).

Drawing on 52 interviews with financial economists, quants, and other derivatives market practitioners, as well as a large corpus of publicly available technical documents on counterparty risk management, this paper traces the development and adoption of the models and infrastructures underlying the calculation of these 'credit valuation adjustments' (CVAs) by large 'dealer' banks that make markets in OTC derivatives from the early 1990s until 2007 and their subsequent evolution once the requirement to account for counterparty risk was incorporated into financial accounting standards. In doing so, this paper makes two primary contributions to the emerging literature on fair value and the social studies of accounting and finance more generally.

First, the paper represents (as far as the author is aware) the first detailed historical study that addresses how fair value accounting has shaped the financial modelling and valuation practices used by market participants. As such, the empirical material presented in this paper draws new links between the social studies of finance and accounting, two fields that have largely evolved independently from one another despite commonalities in their subject (Vollmer, Mennicken, and Preda 2009). Moreover, the hybrid theoretical approach employed within this paper, which draws upon work on institutional logics from the organizational institutionalist literature as well as actor-network-inflected work from the social studies of finance, addresses a recognized need within both of these literatures to understand the benefits and drawbacks of combining these perspectives (c.f. Thornton, Ocasio, and Lounsbury 2012, 141; MacKenzie 2017). In this respect, this paper highlights the importance of both meso-level institutional factors and micro-level material factors in shaping the development and adoption of novel calculative practices .

Second, the paper calls into question the assumption that the adoption of fair value by the FASB simply reflected a pre-existing consensus among market participants in favor of techniques drawn from financial economics. This paper shows that in the case of counterparty risk, large dealer banks developed their own solutions to the problem of assigning a monetary value to counterparty risk in line with their own organizational practices and cultures, which were broadly organized around two distinct 'logics' of 
valuation and risk management. While the practices used by a relatively small group of elite investment banks drew from and were closely aligned with the field of financial economics, many commercial banks instead preferred a set of valuation techniques that aligned more closely with their own existing practices of loan credit risk management. Indeed, the use of CVA valuation practices grounded in financial economics - particularly the 'bilateral' market-based form of CVA that eventually came to be implicitly promoted by FAS 157 and IFRS 13 - was by no means universal prior to the switch to fair value. Moreover, this paper suggests that their adoption did not come about 'naturally' through a process of arbitrage or because of their inherent technical superiority. Instead, these investment banks actively sought to use their institutional power to create coercive, mimetic, and normative pressures on other banks to adopt these market-oriented valuation techniques. In this context, the FASB's adoption of fair value accounting should be understood as an institutional development that came to 'tip the balance' in favor of these dealers' preferred valuation practices.

As such, this paper suggests that the mechanisms through which financial economics' shaped the emergence of fair value accounting were more complex than existing work suggests. In addition to shaping the rhetorical discourse around fair value measurement among standards setters - which is already wellestablished in the literature - financial economics was influential in the development of the material calculative practices used by a small set of influential market participants. It was the close alignment of these micro-level practices with the emerging fair value agenda, and these banks' active role in shaping institutional developments that supported the use of these practices, that was primarily responsible for leading dealers to standardize upon bilateral market-based CVA.

\section{Theoretical Approach}

In examining the relationship between the emergence of fair value and the development of counterparty risk modelling practices and infrastructures, this paper draws upon two distinct practice-oriented theoretical: organizational institutionalist theories of practice adoption and work within the social studies of finance and accounting on the development and adoption of calculative practices, devices, and infrastructures. The mixing of multiple theoretical traditions inevitably creates epistemic and ontological tensions. However, when studying the institutionalization of highly technical practices, I suggest that the complementary benefits that arise from combining these perspectives outweigh the resulting theoretical drawbacks. Moreover, particularly within accounting studies, scholars are increasingly mixing both approaches in order to understand how new valuation practices develop and become institutionalized (c.f. Modell, Vinnari, and Lukka 2017). 
What factors shape the development and adoption of novel calculative practices and devices? On the one hand, the relatively older theoretical traditional of organizational institutionalism once seemed to provide a relatively straightforward answer to this question in the form of the so-called 'two-stage' adoption model (Tolbert and Zucker 1983): While the initial development and adoption of novel practices was thought to be driven by technical characteristics such as efficiency, practices were thought to become legitimized after some threshold after which point their adoption was thought to be driven by a process of institutional isomorphism (DiMaggio and Powell 1983), eventually resulting in uniform adoption throughout the field. In recent years, however, a growing body of work has emerged that has called into question this simple model of adoption. We see, for instance, a growing attentiveness to how adoption decisions are driven by a range of field-specific factors including the network position of organizations (Compagni, Mele, and Ravasi 2015), their desire to avoid stigma (Carberry and King 2012) or to adhere to a norm of progress (Nijholt, Bezemer, and Reinmoeller 2016). More importantly for this paper, researchers have begun to challenge the distinction that institutional theory makes between technical criteria and institutional factors by showing how technical criteria tend to be evaluated within particular institutional logics (Lounsbury 2002).

While the study of practices occupies a central role within institutionalist approaches, they have generally not been used to study the material modelling practices and calculative devices that constitute modern finance. By contrast, these elements have instead primarily attracted attention within the social studies of finance (SSF). Researchers within the SSF have produced detailed historical and ethnographic accounts exploring the historical development of particular financial models and related infrastructure that constitute and shape modern financial markets. Despite its differing focus, the SSF's approach to the theorization of practices is broadly complementary with the institutionalist tradition. Indeed, organizational institutionalism's growing focus on the embeddedness of technical criteria within particular institutional logics is consonant with a long tradition of work within science and technology studies (STS), which has emphasized the heterogeneity of the practices, tools, and conceptual ontologies that are used to produce knowledge across the sciences and how these elements tend to be evaluated within particular 'epistemic cultures' (c.f. Barnes, Bloor, and Henry 1996; Knorr-Cetina 2000). Recent work in the SSF has drawn upon this insight to show how financial markets tend to be composed of multiple 'evaluation cultures': Among other elements, these 'cultures' consist of shared set of evaluation practices, ontologies, and discourses that practitioners deploy to value financial assets according to these beliefs, and provide justifications for those valuations to other financial market participants (D. MacKenzie and Spears 2014). Like the concept of institutional logic, 'evaluation culture' is intended to capture both normative beliefs and material practices. Moreover, much like how institutional logics are thought to enable field participants to attribute meaning to social interactions, evaluation cultures arise because of the need to communicate information and 
coordinate action among market participants and actors within financial organizations (Donald MacKenzie and Spears 2014). Both of these perspectives acknowledge, however, that participants within a market or field routinely engage in 'bricolage' - or creative tinkering - which often involves the borrowing of practices developed within different cultures or logics (c.f. MacKenzie and Pablo Pardo-Guerra 2014; Rao, Monin, and Durand 2005).

Despite these commonalities, SSF-inflected perspectives tend to differ from those in the organizational institutionalist literature in several important ways that are analytically useful. For instance, while the definition of institutional logics encompasses material practices (see Thornton and Ocasio 1999, 804), materiality itself - the sine qua non of SSF-inflected work - does not play a comparably important role in the organizational institutionalist studies of practice adoption. While SSF-inflected work tends to emphasize that technical factors are evaluated within particular cultures, material factors are given an agency of their own that is not reducible to culture within the SSF, a tendency that is attributable to the influence of actornetwork theory on much work within this field. Thus within SSF-inflected accounts of finance, 'scales are not stable' (MacKenzie 2009), which is to say that small, seemingly insignificant technical details can be extremely consequential in shaping the macro-level behavior of markets and market participants. These approaches thus tend to emphasize the collection of detailed historical and ethnographic work on the development of specific calculative practices and infrastructures, perhaps at the expense of attention to meso-level dynamics at the level of the field.

By contrast, organizational institutionalist work tends to place a much greater emphasis on the importance of coordinated field-level dynamics, as well as developments in adjacent fields, in shaping the adoption of practices (c.f. Greenwood, Suddaby, and Hinings 2002; Fligstein and McAdam 2012). Financial organizations such as banks often exhibit a high degree of coordinated collective behavior - as the case I present in this paper suggests - particularly in their interactions with external audiences, such as regulators. To that end, field theory and other institutionalist approaches explicitly theorize features that SSF-inflected accounts tend to overlook with their attention to technical details: perhaps most notably, the importance of collective action among members of organizational fields in institutionalizing certain practices as legitimate. In this respect, combining an organizational institutionalist perspective with the SSF's focus on materiality helps to address an acknowledged weakness of work within this latter field. Indeed, the SSF has been specifically critiqued for drawing an analogy between scientific practice and market making: By treating the trading floor as an analogue of a scientific laboratory and focussing attention on the devices and practices that underpin the production of knowledge within financial institutions, critics argue that the field has inadvertently downplayed the role of institutions, power, and politics in the development of new forms of finance (Mirowski and Nik-Khah 2008; Fligstein and Dauter 2007, 107). 
Moreover, existing work in the SSA has highlighted how the emergence of new calculative practices is often accompanied by - and sometimes driven by - the emergence of new forms of organization and novel techniques of government and control (see Miller 1994; Miller and Rose 1990). This perspective suggests that an important element of financial evaluation cultures is not only the practices they use to evaluate the risk of securities, but also the broader practices they use to control and govern these risks. As we will see in the history that follows, the application of techniques drawn from financial economics and the evaluation culture practiced by derivatives traders to the valuation of counterparty risk enabled new methods for governing and controlling counterparty risk-taking activities by traders and other actors within banks.

Finally, given its focus on financial markets compared to the more general empirical orientation of organizational institutionalist work, SSF-inflected work tends to be much more attentive to the role of market-oriented activity in shaping the development and adoption of new practices. Arbitrage, the identification and execution of trading opportunities that produce identical cashflows but are priced differently and thus present opportunities for profit, has attracted considerable attention by the SSF. Indeed, much of the existing SSF-inflected work on the 'performativity' of economic models has focused on how the adoption of valuation models and practices can come about through both the development of new markets as well as arbitrageurs within those markets seeking to exploit inconsistencies in securities prices (c.f. MacKenzie and Millo 2003; Beunza and Stark 2012). SSF scholars have also focused on some of the more classical social processes responsible for the adoption of practices, including imitation (MacKenzie 2003). However, the role of more formal institutional processes - including interaction with regulatory bodies like accounting standard-setters - has not attracted comparable attention within this field.

With those points in mind, the research upon which this article is based supports the following four propositions about the development of new financial practices:

First, organizations within the financial markets tend to be embedded within multiple institutional logics, and as a consequence, tend to employ distinct - and sometimes conflicting - evaluation practices for managing, assessing, and controlling the risks they face. Within the US, for example, entities that were classified as commercial and investment banks under the Glass-Steagall Act of 1934 historically quantified and managed the primary risks they face - credit risk and market risk, respectively - using clusters of practices that entailed distinct ontologies and epistemologies of risk: i.e. how risk is best measured and managed. As we will see, commercial banks tended to measure and manage the primary risk they faced through an actuarial logic that emphasized the use of long-run historical data and the judgment of a trained credit analyst in measuring credit risk, as well as the use of loan-loss reserves and credit limits in managing that risk. By contrast, investment banks came to practice a logic of risk management that was heavily influenced by financial economics, which assumed that market prices, rather than long-run historical data, 
is the best gauge with which to measure risk. Moreover, investment banks primarily managed market risk through hedging: i.e. the purchase/sale of financial securities that are expected to generate off-setting returns to the risk being hedged.

Second, consistent with a growing body of work in the sociology of finance (c.f. Engelen et al. 2010; MacKenzie and Pablo Pardo-Guerra 2014), the empirical material in this paper supports the notion that the development of new financial modelling activities occurs through a process of 'bricolage'. As such, the development of new models and related infrastructures occurs through the application, modification, and recombination of existing modelling practices to new problems. Thus when organizations that are embedded within distinct logics of practice face a shared risk, they will often develop different - and even contradictory - solutions to quantifying and managing that risk. For example, OTC derivatives combine features of both loans and securities, the two classes of financial assets that were the province of US commercial and investment banks, respectively. Because these securities combined both of these features, both types of organizations became involved in the OTC derivatives markets, and thus came to share a new type of risk: counterparty risk. However, because commercial and investment banks tended to approach risk management through distinct institutional logics, they developed distinct solutions to the problem of quantifying and managing counterparty risk.

Third, the lack of consensus over how risk ought to be quantified and managed that tends to result from this process of bricolage generates conflict both between organizations within the field and within organizations themselves. At the level of the field, the use of conflicting practices creates a problem of legitimacy for the field as a whole, especially among outside audiences such as regulators. In this respect, this paper's empirical account suggests that market fields exhibit a similar dynamic to one that organizational sociologists have long noted at the level of individual organizations: that non-conformity can induce inferior evaluations by outside audiences (Zuckerman 1999). In the case of counterparty risk, the initial absence of consensus among dealer banks over whether and how counterparty risk should be valued called into question the OTC derivatives markets' capacity to self-regulate, a sense that became particularly acute following a number of high profile failures involving derivatives in the mid-to-late 1990s. At the same time, a lack of consensus over the need to explicitly value counterparty risk created conflicts between traders and risk managers within major dealer banks, as the introduction of counterparty risk management practices tended to put traders at a competitive disadvantage compared to traders at banks that had not adopted such practices.

Fourth, when evaluative differences arising between these practices cannot be resolved through arbitrage - as they often cannot - market participants, particularly those at the core of a market field, will use their institutional power and influence to encourage the adoption of their own preferred practices among other 
participants. Thus in contrast to much existing work within the SSF, which has focused on how the adoption of new financial models is facilitated via arbitrage, the homogenization of techniques used to value counterparty risk came about instead through institutional, rather than market-based, mechanisms. Because a CVA is tied to the credit worthiness of a dealer bank and its counterparty, it is not possible for a third party participant to arbitrage a bank mis-valuing the default risk embedded within its own derivative contracts. Moreover, banks that underpriced counterparty risk would, in many cases, be rewarded with a greater share of business than their competitors who did not value these risks as prudently. When combined with the threat to legitimacy that these valuation discrepancies posed to the field as a whole, banks thus faced a collective action problem. In response, a number of banks at the core of the derivatives field - most notably, Goldman Sachs and J.P. Morgan - used their institutional clout to promote the use of these techniques, both within the derivatives market field and in adjacent fields, including the fields of tax and financial accounting.

\section{Methodology, Data and Sources}

Reconstructing the historical development of financial modelling practices creates certain challenges due to the inherently non-public nature of these activities. These challenges have influenced the data collection strategy used to develop the history presented in this paper. The first potential issue is secrecy. Banks are not nearly as secretive about the valuation models examined in this paper as they are with certain other models; for instance, models that their traders use to identify profitable trading opportunities. Yet public information - and in particular, archival sources - about the development of these models is still rather limited.

To address this challenge, this paper triangulates between three distinct sources. The first source of data is 25 interviews with financial economists, mathematicians, quants, and IT professionals who have first-hand experience developing the risk modelling practices examined in this paper. ${ }^{1}$ These interviews took a loosely oral-history form, and interviewees were led through their individual career histories with a focus on how their careers related to historical developments of modelling practices used to quantify counterparty risk. Because 'on the record' interviews can create legal and compliance issues for employees of financial institutions, interviewees working for such institutions were told that their comments would be kept strictly non-attributable. In this paper, interview data sourced from these interviewees are identified by pseudonyms. I have also drawn on an additional 27 interviews that were conducted with derivatives quants,

\footnotetext{
1 All names used in this paper are pseudonyms.
} 
financial mathematicians, and financial economists that did not specifically cover the topic of counterparty risk, but were useful in understanding the financial modelling practices used to value counterparty risk.

Interview data were supplemented and corroborated, first, by an analysis of a large corpus of technical documents from the early 1980s until the present day on the subject of counterparty risk, as well as documents focused on the modelling practices that constitute the culture of no arbitrage modelling. Because many of the practices that were used in the 1980s for assessing credit risk are no longer used in their original form within banks, documents were the essential source of data used to reconstruct these earlier practices. This set of documents included books published by market practitioners, papers published in specialist trade publications (e.g. Risk Magazine and Euromoney Magazine), the text of major accounting standards, as well as documents written by the major auditing firms on the implementation of these standards. One rather unusual source of information that was helpful in understanding the modelling practices used by banks in the early 1990s was the court opinion of a U.S. tax court case between the U.S. government and a large American bank. ${ }^{2}$ The court's opinion describes, in rather intricate detail, the practices used by the bank in question to evaluate counterparty risk in the early 1990s. Another extremely useful set of sources was textbooks on CVA pricing and risk management, which provided important information on contemporary practices (Gregory 2010; Kenyon and Stamm 2012; Cesari et al. 2009).

Finally, these interviews and documents were supplemented by ethnographic fieldwork done at three weeklong derivatives quant conferences in 2012, 2013, and 2014, as well as several smaller conferences focused specifically on the pricing of counterparty risk using the techniques discussed in this paper. Along with the aforementioned textbooks, these instances of fieldwork gave me insight into the practices for quantifying these risks that are currently in use at banks.

These categories of data, of course, have deficiencies. Oral-history interviews, for instance, tend to be vulnerable to interviewees' imperfect memories, while technical documents tend to portray modelling practices in an idealized manner that may not be representative of actual practice. Moreover, because the modelling and evaluation practices that I examine in this paper are largely proprietary, it is unfortunately not possible to reconstruct a completely accurate picture of the techniques used by banks to model and evaluate counterparty risk. However, my hope is that through careful triangulation between interview data and documentary analysis, I have constructed a reasonably accurate account of the broad evolution of these techniques over time, as well as the social and technical drivers of these changes.

\footnotetext{
${ }^{2}$ See: Bank One Corporation and Affiliated Corporations v. Commissioner of Internal Revenue, Nos. $5759-95$ and $5956-97$ (U.S. Tax Court, 2 May 2003).
} 


\section{Counterparty Risk and OTC Derivatives}

The era of financial deregulation that began in the United States in the 1980s brought about profound changes not only to the field of finance, but to the broader social organization of the American economy (Davis and Mizruchi 1999). At the center of these changes was a gradual switch from a regulatory logic centred around Glass-Steagall era demarcations between commercial and investment banks to a market logic in which new hybrid products and organizational forms gained increasingly legitimacy (Lounsbury 2002). One of the most significant of these hybrid products were so-called 'over-the-counter' (OTC) derivative contracts: customized financial contracts that allowed market participants to speculate on or hedge against movements in market interest rates and other market prices.

In contrast to their exchange-traded counterparts, OTC derivatives are not traded on a public exchange but instead are privately negotiated and settled between the two parties specified in the derivative's contractual terms. Large commercial and investment banks, known as 'dealer banks', came to play an important role within these markets by serving as 'market makers' in these contracts for other organizations, including other banks, financial institutions, and non-financial corporations. As market makers, dealer banks stand ready to enter into a wide range of contracts with other market participants, and then attempt to hedge (i.e. reduce or eliminate) the resulting risks by trading in other financial instruments, including shares of stock, bonds, or other derivatives depending on the type of derivative being hedged.

As Funk and Hirschman (2014) note, OTC derivatives such as swaps blend characteristics of loans and securities, two categories of financial assets that until the repeal of the Glass-Steagall Act were the province of commercial and investment banks, respectively. By combining features of these assets, OTC derivatives also combined their risks. Like securities such as shares of stock, OTC derivatives create 'market risk' to those who use them: the risk that a movement in the market price or interest rate specified in a derivative's contractual terms will change, thereby creating a financial loss, as is illustrated in Figure 1 in the case of a derivative known as a fixed/floating interest rate swap. However, like loans, OTC derivatives are effectively promises to exchange cashflows over time; as such, they create 'credit risk' to their users: the risk that one party may declare bankruptcy or be unwilling to meet its obligations under the derivative contract. Dealer banks that became involved in the OTC derivatives markets thus needed to develop practices to evaluate and manage both of these forms of risk.

With respect to the evaluation and management of market risk, derivatives practitioners within commercial and investment banks quickly converged upon a relatively uniform set of practices drawn from financial economics that emphasized a particular logic of risk evaluation and management. While some practitioners in these markets initially valued certain OTC derivatives using valuation practices borrowed from the bond 
markets, by the mid-to-late 1980s dealer banks increasingly adopted a cluster of mathematical modelling practices that were intellectual decedents of the Black-Scholes-Merton model with its focus on dynamically hedging risk (Miron and Swannell 1991; Hansell 1991). Indeed, derivatives market practitioners within both commercial and investment banks were particularly influenced by Merton's derivation of the BlackScholes model, which was based on the logic of replication: Merton showed that if it were possible to construct a dynamically-adjusted portfolio consisting of shares of stock and cash that together exactly mimicked (i.e. 'replicated') the behaviour of the stock option, and the value of that replicating portfolio could be determined, then the price of the stock option should be equal to the cost of constructing the replicating portfolio. If these two values were different, then it would be possible (again, in principle) to simultaneously buy the cheaper and sell the dearer of the two in unlimited quantities thereby earning a riskfree arbitrage profit, a situation that financial economists like Black, Scholes and Merton believed to be sufficiently anomalous such that it can safely be assumed impossible. But more importantly to these practitioners, the Black-Scholes model could - again, in principle - also be used to hedge (i.e. cancel out) any risk that a bank or financial institution assumes when it sells an option to one of its clients by building a portfolio that was equal to the inverse of the model's proscribed replicating strategy. In doing so, the portfolio would become 'delta-hedged': any changes in the option's value caused by small movements in the underlying stock's price would be effectively cancelled out by the trader's holdings in the stock itself.

Having become established as an exemplar of the use of mathematical modelling to manage financial risk, the Black-Scholes model's emphasis on hedging came to deeply influence the evaluation and management of the risks associated with not only options, but a range of other OTC derivatives including swaps. In the case of swaps, for instance, by the late 1980s large dealer banks began to abandon existing techniques for valuing swaps that had been appropriated from the bond markets in favor of a new set of practices such as the 'zero-coupon' approach to swap pricing. Writing in Euromoney, a popular trade publication at the time within the London-based Eurocurrency markets, Cooper (1987) explains the appeal of the so-called 'zerocoupon' approach: For swap dealers who first adopted it in the 1980s, the technique allowed one to 'net out the whole basket of cash flows' that constituted the bank's swap portfolio and hedge them together. Along with the zero-coupon approach to swap pricing, practitioners in these markets also widely adopted a modified version of the Black-Scholes model (which Fischer Black himself had developed to price commodity options) in order to value the most popular over-the-counter options, which are known as 'caps' and 'swaptions'.

There are several related practices that came to be shared by derivatives market practitioners that bear upon the historical account developed in this paper. First, as a consequence of the deep connection between pricing and hedging within the logic of the Black-Scholes model, practitioners of this culture came to share 
a market-oriented epistemology, which sees the market prices of the assets used to hedge a derivative - as opposed to, for example, the trained judgment of an analyst - as the preferred source of reliable information as to the value and risk of the derivative. For practitioners of this culture, a model must accurately fit (or 'reproduce' in practitioner parlance) the quoted market prices of the instruments used to hedge a derivative to accurately value the derivative, even if those prices are 'wrong' in the absolute sense. (If the model failed to fit the prices of those hedging instruments, it would also fail to recommend an appropriate hedging strategy to the trader.) Thus, when building models, practitioners of this culture follow a modelling practice known as 'market-implied' calibration: Rather than choose the parameters of their models through historical analysis of asset prices or by relying on their own subjective judgment, models are designed to derive these parameters directly from the market (c.f. Rebonato 2004; Wilmott 2007, ch. 17; Ayache 2007).

Closely related to the use of market-implied calibration is the assumption of market 'completeness': a notion, originating within mid-twentieth century economic theory, that there exists at least one tradeable financial security with which one could replicate or hedge every risk factor affecting the value of a derivative (Arrow 1964; Harrison and Pliska 1983). The Black-Scholes model implicitly makes this assumption, as do many models that derivatives traders and quants use in their day-to-day work. The assumption of completeness is a rather strong one about the nature of financial markets: While 'incomplete markets' models - i.e. models that do not require this assumption of completeness - have gained some popularity among traders and quants in the last several years, these models require one to specify additional parameters that cannot be directly calibrated using market prices, and thus tend to be less practical. While many traders and quants maintain a skeptical attitude towards the assumption of market completeness, particularly since the financial crisis, the more fervent adherents to the culture see the derivatives markets as helping to promote a world of ever increasing market completeness, in which an increasingly large set of financial risks can be eliminated through trading. Indeed, Merton himself expressed this view through the image of a 'financial innovation spiral'. In Merton's view, the growing liquidity of existing financial instruments would enable the creation of new financial derivatives that could be hedged using these existing instruments (using models like the Black-Scholes model), thereby offering market participants the opportunity for managing their own risks with greater precision. The growing liquidity of these derivatives would, in turn, allow for the development of even more derivatives, thus allowing for an even greater number of risks to be managed (Merton 1995, 27).

\section{The Problem of Credit Risk}

Missing from these modelling practices, however, was a focus on credit risk, the second major form of risk that affects the value of OTC derivatives. Indeed, the Black-Scholes model, the exemplar par excellence of 
no-arbitrage modelling, implicitly assumes that there is no chance that an option seller will go bankrupt and fail to make good on its obligation to buy or sell the underlying asset when an option expires. As a consequence, credit risk was initially ignored by many of these practitioners - a choice that was, in many ways, in traders' own self-interest, as it allowed them to book as profit what was in fact compensation for taking on credit risk. Benjamin, a former swaps trader who worked at Citi in the early 1990s, explained in an interview that few traders were aware of the credit risk of swaps and derivatives when he first joined the firm: 'I'm not sure how prevalent that the idea that you were actually taking credit risk was. I think most people considered [the profits] as market value and you had these outsize profits because you were providing liquidity or something like that' (Interview with Benjamin).

Derivatives market practitioners working within commercial and investment banks were initially able to ignore credit risk for different reasons. Investment banks, as Brown and Smith (1993) noted at that time, generally lacked the credit risk assessment expertise of commercial banks, given that their business was traditionally focused on securities issuance and dealing. With the exception of corporate bonds and certain government bonds, credit risk was not a major risk factor that these organizations needed to manage in their day-to-day operations. For these reasons, investment banks preferred to use legal mechanisms - such as collateral or letters of credit - to eliminate the credit risk of their swap counterparties, rather than attempting to evaluate it quantitatively (Brown and Smith 1993, 97).

Banks' credit departments, the group traditionally responsible for managing credit risk within these organizations, tended to be separated, both organizationally and culturally, from banks' derivatives practitioners. As a consequence, coordination between the two groups was often stymied. In the case of corporate loans, banks' credit departments were responsible for providing credit assessments to the bank's lending officers about the credit quality of a prospective borrower, as well as establishing credit exposure limits and reserves to protect the bank against unanticipated defaults by its borrowers. ${ }^{3}$ The size of this reserve - and the interest charged to the borrower - would depend upon the borrower's credit quality, as determined by the bank's credit staff using historical data on borrower defaults.

By the time the OTC derivatives markets were emerging in the early 1980s, commercial banks had rationalized certain elements of the credit assessment process - for instance, by establishing internal rating

\footnotetext{
${ }^{3}$ As its name suggests, a credit limit refers to a hard limit on the bank's level of credit exposure for a single borrower. A reserve, on the other hand, refers to a negative entry in the asset portion of the bank's balance sheet (what accountants refer to as a 'contra-asset') that is used to report any anticipated losses from the bank's loan portfolio, which would be funded by charging a higher interest rate to the borrower.
} 
systems to determine borrower credit quality. ${ }^{4}$ Yet the practice of credit risk assessment very much depended upon the expert judgment of the bank's credit officers, who were responsible for developing and maintaining criteria that determined the rating category into which each borrower would be classified. In this respect, the logic of risk evaluation underlying this cluster of techniques differed considerably from the market logic practiced by derivatives practitioners, which had been heavily influenced by financial economics. Indeed, banks' credit officers were generally trained in the traditional techniques of corporate credit assessment, which emphasized careful analysis of the borrowing firm's accounting statements and business model by a trained analyst, as well as the capacity of an analyst to make reliable judgments about the creditworthiness of a potential borrower. According to Saunders and Allen (2002), bank credit analysts were often trained to make lending decisions based on 'the "five C's" of credit for a particular company: its character (i.e. its reputation and repayment history), its capital structure, its capacity to repay, the collateral available to back its loans, and the current state of the business cycle. One of the best contemporary descriptions of the practices of corporate credit assessment comes from T.H. Donaldson (1983), who in the early 1980s was the Vice-President and European Credit Officer at the Morgan Guaranty Trust in London, a prominent commercial bank that would later become a part of J.P. Morgan. His 1983 book, Understanding Corporate Credit, indicates just how different the character of these practices was from those of the culture of no-arbitrage modelling. Donaldson's book instructs the intended reader - a newly hired credit analyst - how to make a judgment about the credit quality of a company by carefully examining its balance sheet and profit and loss statement, as well as its degree of liquidity, leverage, cash flow situation, and even 'non-financial aspects of the company', including the quality of its managers, its labour relations, and so on. In contrast to the market-oriented epistemology of derivatives quants and traders, Donaldson emphasizes the importance of trained, expert judgment in evaluating the credit risks of a company. He encourages the analyst to examine a prospective borrower's financial situation in a 'dispassionate' manner and the importance of 'clear thinking about the fundamentals of a credit' (Donaldson 1983, 274). He also discusses at length the importance of clear writing and presentation to clarify one's thinking about the risks associated with a borrower, and to demonstrate this reasoning to the bank's management (Donaldson 1983, 273).

The dispositions and practices of banks' credit officers often came into conflict with those of derivatives practitioners. For instance, with their focus on hedging, the practices used by derivatives traders and quants

\footnotetext{
${ }^{4}$ These systems are proprietary, and thus public information of their technical details is limited. However, based on interviews with credit personnel at the 50 largest U.S. banking organizations in the late 1990s, Treacy and Carey (2000) describes the credit rating systems in use at these organizations. Treacy and Carey note that even in the late 1990s, the subjective judgment of banks' credit staff played an essential role in determining the credit risk of an individual borrower (Treacy and Carey 2000, 177).
} 
implicitly encouraged traders to grow their trading books to a large size, as a large portfolio of derivatives naturally tends to have many off-setting derivatives positions and is thus less costly to hedge. By contrast, the slower, more prudent approach to credit risk management used by banks' credit officers tended to frustrate fast-paced derivatives traders. Indeed, David Rowe - a notable counterparty risk practitioner notes this tension in his own retrospective account of the evolution of counterparty risk management techniques (Rowe 2003). That this tension existed is also corroborated within T.H. Donaldson's work: Six years after the publication of Understanding Corporate Credit, Donaldson (1989) published a new book that examined the credit risks embedded in OTC derivatives and other 'off-balance sheet' instruments that had become popular in the intervening years. In the introductory chapter, he points to 'the tendency to overlook risk in the rush to get business; and the resulting downgrading of risk specialists, and perhaps especially credit specialists, at a time when arguably the need for their knowledge was greater than ever' as a major problem facing commercial banks in the late 1980s (Donaldson 1989, 19). Also writing in 1989, Schuyler Henderson - then a partner at the London-based law firm Sidley \& Austin - wrote in an article in 1989 on the credit risk of swaps that 'credit decisions are made quickly, sometimes without the detailed analysis customary in the past.' Moreover, 'the bankers on the front line in many instances are now dealers rather than credit officers. Their training is in market pricing, not credit analysis' (Henderson 1989, 382).

Conflicts were also apparent in how each group thought about risk, i.e. each group's respective ontology of risk. Alan, a former swaps trader who worked at Banker's Trust - an American commercial bank that became involved in swaps and derivatives trading - and later J.P. Morgan, explained in an interview the lack of understanding between practitioners of the culture of no arbitrage modelling and banks' credit officers:

It was one of those things where most of the people involved in derivatives and swaps were mathematicians or people with a maths background. And derivatives were so new and sexy that people said, "Oh, we understand cash-flows and future cash-flows". Because people in loans People in loans didn't understand future cash-flows. They understood [credit] risk. They said, "You look good for 30 million, so I will lend you 30 million". (Interview with Alan).

As Alan's remarks suggest, while derivatives traders thought primarily about risk in mathematical terms e.g. in terms of a derivative's model-calculated risk sensitivities - commercial banks' credit officers primarily thought in terms of a bank's credit exposure to a particular borrower. Yet compared to the credit exposure of a traditional bank loan, the credit exposure of even a relatively simple OTC derivative such as an interest rate swap is a much more complicated object, as is illustrated in Figure 2 in the case of a fixed/floating interest rate swap. As Schuyler Henderson noted, a swap's credit exposure 'cannot be precisely calculated prior to an actual default. The counterparty does not know how rates will move or their level at an indefinite time in the future. At best, when the counterparty enters into the swap, it can make a rough estimate of the range of exposures depending on theoretical rate movements' (Henderson 1989, 374). 
How should one set a credit exposure limit when credit exposure itself is an uncertain quantity? Even a well-informed credit officer who understood that OTC derivatives contained credit risk immediately ran against the problem of lacking the ability to manage this credit risk using traditional credit risk management practices.

Given investment banks' preference for using legal mechanisms to reduce credit risk and the organizational separation of derivatives and loans practitioners within commercial banks, it is not surprising that early efforts to manage the credit risk of OTC derivatives focused on the development of legal techniques to reduce credit risk, rather than attempting to quantify or value this risk outright. ${ }^{5}$ Most notable of these were the development of techniques for enabling the exchange of 'margin' (i.e. collateral) between derivatives counterparties to cover any potential credit losses (Flanagan 2001). However, the use of collateral as a primary mechanism for managing derivatives credit risk reinforced the organizational separation between the evaluation and management of credit and market risk, the second of which was largely the responsibility of banks' derivative practitioners. Indeed, Thom, a former derivatives trader who worked at Banker's Trust in the early 1990s, explained in an interview that when he began working in the markets, the credit risk of a trade was seen as 'a function of the collateral' underlying that trade, rather than a risk that could be valued or quantified explicitly. And because traders' models did not take credit risk into account, they did not account for the credit quality of the counterparties involved when pricing new derivatives for their clients. Instead, during this time the market practiced what Henderson refers to as an 'all or nothing approach' to valuation (Henderson 1989, 384-5), an approach that is independently described by Brown and Smith (1993): If the counterparties were sufficiently low risk, a derivative would be contracted at the price produced by traders' models (which assume no risk of default); if not, the swap would not be done at all. In principle, if a prospective client had a low credit rating, it could employ legal techniques (e.g. collateral) to 'enhance' the credit quality of the swap so that its risks were in line with the prices produced by a trader's model.

This tendency to ignore the impact of credit risk seems to have impacted how OTC derivatives were priced in the broader market. Publications on the derivatives markets from the 1980s and early 1990s suggest that the market prices for swaps did not differentiate between low and high risk counterparties, in contrast to the markets for loans and corporate bonds where there was a strong relationship between the credit quality of a borrower and the perceived value of its debt. A 1984 issue of American Banker, a popular trade newspaper during this time, quotes a Vice President at the investment bank Salomon Brothers: 'One of the

\footnotetext{
${ }^{5}$ For example, a chapter on 'Credit Risk and Swap Exposure' written by Henderson (1983) in one of the earliest books on swap financing is solely focussed on legal remedies to the credit risk underlying these contracts.
} 
problems is that there is very little quality- spread differential in the swap market [...] By definition, a lower-quality credit should be paying up for a swap, but they're not' (Zigas 1984). For these reasons, by the mid-1980s financial regulators became increasingly concerned about the credit risks banks were accruing as the OTC derivatives markets grew exponentially larger, and the effects these risks could have on the stability of the financial system. A 1987 article published by the Federal Reserve Bank of Kansas City notes that 'There is a fear' among regulators 'that to gain market share in interest rate swaps, intermediaries may be underpricing the services they provide'. In particular, regulators feared that 'new entrants into the swap market or existing participants in adverse financial circumstances might be too aggressive in seeking out new swap business to compensate for losses in traditional lending activities' (Whittaker 1987, 9). Indeed, the existence of counterparty risk creates a problem within banks that economists refer to as 'adverse selection': In this case, market participants that are riskier (i.e. more likely to go bankrupt) will generally be willing to pay more to a bank to enter into a given type of derivative contract, in much the same way that riskier borrowers will generally be forced to pay a higher interest rate on a loan. Yet derivatives traders tended to be compensated based on the profitability of their trading activities - often measured using a derivative's model-calculated price - thus creating a strong incentive for traders to accrue large credit risks to banks that only become apparent over longer time horizons.

To ameliorate these governance problems, a number of derivatives dealers came to develop practices to explicitly value counterparty risk. In doing so, however, dealers did not start from a blank slate; instead, banks largely developed solutions to the problem in line with their own firm-specific practices of financial modelling and risk management. Broadly speaking, banks developed two sets of approaches to value counterparty risk. These approaches were homologous to the historical separation enforced by the GlassSteagall Act between commercial banks, whose activities were historically limited to issuing loans and taking deposits, and investment banks, which were allowed to engage in securities trading. Large commercial banks such as Citi incrementally adapted their existing credit risk management techniques that they had long used to manage loan risk to manage derivatives counterparty risk. These techniques used historical data on credit defaults, as well as the trained judgment of credit analysts, to determine an appropriate amount of money to hold in a credit reserve against the risk of possible default. By contrast, in line with their orientation towards securities trading, a small group of derivatives-oriented investment banks came to treat the valuation of counterparty risk as a derivatives pricing problem in and of itself, and sought to extend techniques from the culture of no arbitrage modelling to the valuation of counterparty risk. In the following two sections, I briefly outline the development of each of these clusters of practices. 


\section{Historical CVA: 'Loan Equivalent' Counterparty Risk}

Large commercial banks such as Citi developed a set of practices that incrementally extended these banks' existing practices for managing loan credit risk to the management of derivatives counterparty risk. At these banks, the counterparty risk of swaps and other OTC derivatives was measured in 'loan equivalent' terms: in other words, the counterparty risk of a derivative was translated into units of a hypothetical loan with the same counterparty. Once expressed in 'loan equivalent' units, the counterparty risk of a derivative was evaluated and managed as if it were just another loan in the bank's loan portfolio. A bank could, for example, establish firm-wide credit limits that would apply to both its lending bankers and derivatives traders, as well as firm-wide credit reserving policies that would determine how much profit would need to be diverted into a credit reserve to cover any losses that might occur due to credit defaults. The size of this reserve would depend on the counterparty's risk classification (as determined by the bank's credit department) and the historical probability of default of that class of borrowers. In this arrangement, derivatives traders were given responsibility for managing the market risk component of the banks' derivatives transactions, which they controlled by hedging this risk in accordance with no arbitrage modelling practices drawn from financial economics. Control of the credit risk component, in contrast, ultimately lay with the bank's credit department, which became responsible for establishing the percounterparty exposure limits and reserving policies to which lending bankers were also subject.

The problem of extending banks' loan risk management techniques to the management of derivatives counterparty risk was, on the one hand, a problem of commensuration. Solving it, however, was ultimately a material problem for counterparty risk practitioners. Initially, large commercial banks like Citi modified a set of calculative practices that had been developed by the Basel Committee for Banking Supervision to determine bank regulatory capital. Indeed, the BCBS itself faced the problem of commensurating between loan and derivatives credit risk whilst developing the first set of Basel capital adequacy standards in the late 1980s. To commensurate between the credit exposure of loans and OTC derivatives, the Basel Accords provided a simple formula that expressed the exposure of both sets of instruments in terms of the instrument's 'current exposure' (measured as its current value) and its 'potential future exposure'. To reduce the complexity of the framework, the Basel I accords defined the 'potential future exposure' of each instrument using a simple mathematical heuristic: as the product of the notional value of the instrument and an instrument-specific credit risk 'add on' value provided by the Basel Committee, which had been 
calculated as a part of a modelling exercise that had been jointly conducted by the U.S. Federal Reserve and the Bank of England to determine the average credit risk of a variety of financial instruments. ${ }^{6}$

The Basel 'add-on' formula provided a much-needed heuristic that banks' credit departments could use to map their existing credit risk management practices onto OTC derivatives and thereby commensurate between the credit risk of loans and derivatives. For example, credit limits could be set relative to a counterparty's total loan and derivatives exposure, while reserves and capital could be allocated in accordance with internal ratings and qualitative credit analysis conducted by the bank's credit staff.

Citi and many other banks initially managed derivatives counterparty risk by developing their own, more elaborate, versions of the Basel I 'add on' framework. Sam, a counterparty risk quant at Citi, explained in an interview that when he first began working at the bank, he and his colleagues focused on developing enhancements to the 'add on' approach by creating highly granular paper-based tables (or 'grids') that supplied the bank's traders and credit risk staff with appropriate credit risk factors that could be plugged into the Basel formula depending on the type of product being traded, its maturity, tenor, and so on. ${ }^{7}$

Expressed in loan-equivalent terms and managed using credit limits and reserves, derivatives counterparty risk was valued in what were essentially actuarial terms, as Eugene - a counterparty risk quant - explained to me: 'I was an insurance company; I was saying to all of the traders, 'I'm insuring all of your counterparty risk. You pay me premiums, and every so often there will be a blow-up'. For commercial banks with large loan portfolios, this loan-equivalent approach was a 'natural' choice, as Sam explained during an interview:

It was very natural at a commercial bank - when you had, you know, gargantuan commercial loan portfolios to think, 'Well here's another commercial customer. I already lend money to all of the firms I do derivatives with, and I already know how to think about their credit risk.' So, it was very natural to manage that credit risk as another form of wholesale credit risk (Interview with Sam).

The importance of commensuration was also highlighted in an interview with Lawrence, a former chief risk officer at a commercial bank. He explained that commensuration - what he called having a shared 'language' - was essential in maintaining consistent governance of risk taking between lending bankers and derivatives traders:

It gave him that single number, so that if I made a $\$ 100$ loan to that counterparty, and if I had a derivative transaction that was equivalent to $\$ 20$, then he would say, 'my exposure is $\$ 120$ ', as if it were a loan. And he would just add them together. [...] [H]e would have a language between

\footnotetext{
${ }^{6}$ See: Bank of England (1987) and Bond, Murphy, and Robinson (1994).

${ }^{7}$ See: Rowe (2003) for further description of this approach. The court opinion of the FNBC case reveals that the First National Bank of Chicago used a variation of this framework for establishing credit reserves for swaps and other derivatives.
} 
him and the lender, who was all a part of the same risk management family (Interview with Lawrence).

\section{Market-Based CVA: Counterparty Risk as an 'Option' to Default}

While the management of counterparty risk at most commercial banks thus came to be managed according to an actuarial logic in line with their existing loan risk management practices, at a handful of elite investment banks financial economics came to play a much more central role in shaping the development of tools and practices that were used for managing these risks. These practitioners drew on expertise from financial economics to directly extend no arbitrage modelling techniques to allow for the explicit pricing of derivatives counterparty risk itself.

Underlying this set of approaches is the idea that corporate bankruptcy (i.e. default) can be thought of as the exercise of a particular type of financial option. Consequently, this line of reasoning suggests, one can apply modelling techniques that are designed for pricing actual financial options - such as the BlackScholes model - to price the risk of a corporation defaulting on its debt. Robert C. Merton, one of the codevelopers of the Black-Scholes model, originated this idea in a 1974 paper on the valuation of corporate debt (Merton 1974). Like the financial payoff of holding a call option, Merton observed that a firm's equity will be worth the greater of zero and the difference between the firm's assets and its debt. (A call option gives its holder the right, but not the obligation, to buy an asset at a pre-determined price at a future date.) If one can price this default 'option', one can - in effect - assign a market price to the risk of a corporation defaulting and even hedge this risk, as one would a stock option.

Following the publication of Merton's 1974 paper, a large academic literature soon developed in financial economics that extended this approach to a variety of other instruments, including derivatives. Eric Sorensen and Thierry Bollier, two financial economists at Salomon Brothers who had both worked as finance academics before joining the firm, developed what would become the most influential of these approaches (Sorensen and Bollier 1994). ${ }^{8}$ They focused on the specific case of the credit risk of a fixed/floating interest rate swap, one of the most common OTC derivatives. Following Merton, they made a similar observation about the 'option-like' behavior of a swap in the case in which one of its counterparties defaults. Because swaps are bilateral contracts and can take on both positive and negative values for both counterparties, the rules governing the treatment of swaps in bankruptcy suggest that the payoff of holding a swap has a similar option-like structure: If a swap has negative value to a bank (and thus positive value

\footnotetext{
${ }^{8}$ Although they had finished developing this framework by 1990, their work was not made public until 1991, and was only formally published in the Financial Analysts Journal in 1994 (Duffie 2001, 17).
} 
to its counterparty) and that counterparty defaults, then U.S. and English bankruptcy law would require the bank to pay the value of the swap to the bankrupt firm. On the other hand, if the swap has positive value to the bank (and thus negative value to the client), the bank is unlikely to ever recover the value of the swap, as it will be a general unsecured creditor for bankruptcy purposes.

Sorenson and Bollier argued that a credit-risky market participant implicitly sells to its counterparty a sequence of options to default on the swap on each date in which a payment is due. These default options could then be explicitly priced and hedged by trading in what are, in theory, securities with observable market prices. Per Sorensen and Bollier's framework, the value of the swap for each party should be equal to the 'no-default' value of the swap less a credit valuation adjustment for each future payment date. Each of these date-specific credit adjustments could be calculated by multiplying two numbers that one could, in principle, infer directly from market prices: the 'risk-neutral' probability of default of the counterparty (given by the current 'spread' of the counterparty's bonds or other credit-sensitive instrument above the risk-free yield curve), and the quoted price of a 'swaption', a type of derivative that gives one the right, but not the obligation, to enter into an interest rate swap at a later date.

In line with the no-arbitrage modelling practices used by derivatives traders, Sorensen and Bollier's CVA method could, in principle, be applied directly from market prices, in contrast to the 'loan-equivalent' approach to CVA used by commercial banks, which ultimately depended upon the expert judgment of a bank's credit officers. Indeed, the market-implied calibration of either formula is nearly trivial for traders at a large investment bank: Prices for the swaptions could either be directly observed or could be estimated by the bank's own options trading desk using a derivatives pricing model that itself is directly calibrated to observable market prices. Likewise, if there existed financial instruments whose prices were sensitive to the perceived default risk of the bank and its counterparty (e.g. bonds issued by these firms), the probabilities of default could in many cases be calibrated to the quoted prices of those instruments. Sorensen and Bollier's framework had another extremely important point of compatibility with the practices of derivatives traders: in addition to being able to assign a market price to the value of counterparty risk, it allowed the bank to actively hedge this risk, in much the same way as one could hedge the risk of selling an option with the Black-Scholes model.

In their paper, Sorensen and Bollier only examined CVA in the specific case: of a standard fixed/floating interest rate swap. But their work was later generalised to a broader range of derivatives by Darrell Duffie, a financial economist at Stanford University, who became aware of the problem of pricing counterparty risk after meeting Thierry Bollier in the mid-1990s (Duffie Interview). Duffie, along with a graduate student named Ming Huang, later recast Sorensen and Bollier's framework in the framework of recursive utility 
from economic theory (Duffie and Huang 1996), which allowed the technique to be applied to a wide range of financial derivatives (Duffie and Singleton 2003; Canabarro, Picoult, and Wilde 2003).

The market-based CVA approach was also adopted or independently developed by a number of different investment banks and securities trading firms during the 1990s, in some cases with the assistance of financial economists working in both academia and industry. Duffie, for instance, helped promote the approach at Morgan Stanley while consulting for the investment bank in the early 1990s (Duffie Interview). AIG Financial Products (AIG FP), a derivatives trading subsidiary of the large American insurer, also experimented with Sorensen and Bollier's approach according to Louis, a former financial economist who had left academia to work for the firm (Interview with Louis). Within AIG FP, the perceived need to explicitly price the credit risk embedded within swaps and other derivatives was particularly acute, as the firm had developed a reputation for taking on derivatives risks that other trading firms did not want (Hansell 1991).

Yet it was Goldman Sachs and J.P. Morgan, two large derivatives-oriented investment banks, that ultimately came to be the strongest and most influential proponents of market-based CVA. Like Solomon Brothers, Goldman Sachs had a strong orientation towards securities trading, particularly following its acquisition of the commodities trading firm J Aron \& Company in 1981. It also tended to deal with large, established companies that issued bonds, which the bank could 'short' to hedge its counterparty risk. Moreover, the firm had - and continues to have - a strong internal cultural preference for 'marking-tomarket', a practice that later became central to fair value accounting practices. Indeed, Matthew - a PhD in finance who was involved in building Goldman's approach to CVA - emphasized that in contrast to the commercial banks, which 'calculate reserves, based on their assessments of credit worthiness', at Goldman there was a widespread view that, 'everything has a price in the market place; exposures and spreads,' and that 'you should mark your counterparty risk there.' Using Sorensen and Bollier's market-based CVA framework, Goldman's fixed income division set up a separate counterparty risk trading desk to price and hedge the counterparty risk embedded within the bank's swaps book. Under this arrangement, swaps traders were required to pay the market-implied price of the counterparty risk embedded within their swaps to the CVA desk, which would then be responsible for hedging and managing that risk. Gradually, this approach to counterparty risk management was applied to a wider set of financial instruments, including equity and commodity derivatives (Interviews with Matthew and Bryan).

J.P. Morgan was another large, derivatives-oriented bank that enthusiastically adopted market-based CVA during the 1990s. Once a traditional commercial bank focused on corporate lending (with credit assessment practices similar to those of the banks discussed in the previous section), the bank initially used a variation of the 'loan-equivalent' techniques described in the previous section to value the counterparty risk of their 
derivatives portfolios. Throughout the 1980s and 1990s, however, the bank gradually transformed itself into a derivatives powerhouse, and came to apply no-arbitrage modelling techniques from financial economics, not only to create new financial products but to improve the internal management of the bank's employees. These efforts to change the bank's business model were encouraged within by a small cadre of derivatives-oriented bankers led by a banker named Peter Hancock, who had founded the bank's derivatives business in 1991. Hancock's team, which became known as the 'Morgan Mafia' throughout the derivatives industry, is most famous for their role in developing a market for credit default swaps (CDS) and other credit derivatives, which later came to be associated with the subprime housing bubble and the 2008 financial crisis. Yet the initial development of credit derivatives - originally in the form of the BISTRO products discussed by Tett (2009) - was a part of a broader effort by the group to use market-based mechanisms to internally assess the profitability of the bank's activities more effectively. To this end, much like Goldman Sachs, Hancock's team developed a centralized counterparty exposure desk that charged the bank's traders and lending bankers for the market-implied 'price' of the credit risk embedded within their trades and then hedged the bank's aggregate level of credit risk by trading in, among other things, credit derivatives.

\section{Conflict over the Varieties of CVA}

By the mid-to-late 1990s, leading dealer banks had thus developed a number of different approaches to assigning a value the counterparty risk embedded within their derivatives portfolios in line with their own distinctive organizational practices. However, the emergence of these practices created tensions within banks between traders and risk managers and even threatened to destabilize the market itself.

The first source of tension was intra-organizational, and existed between banks' counterparty risk practitioners and derivatives traders. It originated from the way in which the use of CVA - of both the loanequivalent and market-oriented varieties - tended to reduce the profits (and thus compensation) of banks' derivatives traders. Indeed, this was exactly why many banks adopted CVA: the presence of counterparty risk creates an extra cost to the bank selling a derivative that must either be passed on to the client, or deducted from the trading desk's profit to cover the potential loss. However, before the adoption of CVA practices had become widespread, passing this cost on to the client usually meant that a trader would find herself offering uncompetitive prices relative to competitors who neglected to value counterparty risk. Some banks were willing to internalize the costs of CVA to remain competitive: Philip, a member of the 'Morgan Mafia' at J.P. Morgan, explained in an interview that the bank would often issue loans or derivatives at a price below their true value in the hope of winning more lucrative forms of business - such as securities underwriting or mergers and acquisitions deals - from the same client at a later date. In general, 
though, the adoption of CVA tended to reduce the compensation of traders and other front office personnel. Eugene, who was involved in the introduction of CVA to a large French bank, noted that 'I wiped out parts of our business. And nobody was happy of course, because the people in the front office want to make money; they want to get paid well.'

These tensions were exacerbated by a significant shortcoming of early CVA methodologies: By treating the CVA of each derivative in isolation - as one would with a loan - both the paper-based grids used by commercial banks and the Sorensen and Bollier framework did not recognise the marginal credit exposure benefits from hedging, the key risk management technique used by practitioners of the culture of noarbitrage pricing. If, for instance, a trader were to enter into a new swap with cashflows that off-set those of an existing swap with the same counterparty, one could argue that such a swap would decrease, if not wholly eliminate, the original swap's credit risk to the bank. However, these early CVA frameworks would instead report an increase in credit exposure to that counterparty. By failing to take these effects into account, traders argued that they were actively penalized for making trades that improved their bank's credit exposure profile (Rowe 2003). Not surprisingly, CVA, particularly the loan-equivalent formulations used at commercial banks, initially felt alien to derivatives market practitioners. Russell, a derivatives quant who worked at Chase-Manhattan - another large commercial bank that existed in the 1990s before it was acquired by J.P. Morgan - explained in an interview that with respect to the determination of credit limits and reserves: ' $[\mathrm{I}] \mathrm{t}$ was just - whatever this is, it's some corporate thing that has to happen upstairs somewhere on the 48th floor' (Interview with Russell).

This tension shaped the development of CVA technology in a deeply material way. At both sets of banks, counterparty risk practitioners focused on developing computationally-sophisticated CVA methodologies that could take the effects of hedging and netting into account. Among commercial banks, Citi was one of the first banks to do so in the early 1990s. Known as the 'simulation approach' to credit exposure estimation, the method that quants at Citi devised used the same modelling technology that the Bank of England had originally used to calculate the 'add on' parameters that were used in the original Basel capital framework: a technique known as Monte Carlo simulation (Lawrence 1995). Using this technique, a computer could simulate thousands of possible future scenarios for the bank's future credit exposure to a counterparty, in effect producing an exposure 'profile' like that which is illustrated in the bottom panel of Figure 2 but for all derivatives with a given counterparty rather than a single swap. These future exposure scenarios could then be reduced to a loan-equivalent exposure by first calculating the average exposure across all scenarios at each time period (the portfolio's 'expected exposure') and then averaging this expected exposure value across all time periods to produce a single number called the 'expected positive exposure'. 
Investment banks that developed the market-based approach also employed Monte Carlo simulation to build a more computationally-sophisticated CVA methodology. J.P. Morgan, for instance, built a large-scale Monte Carlo simulation system that the bank began developing in 1996, known internally as 'Samprus' (Interview with Roger). Unlike the relatively simple formula-based approach described in Sorensen and Bollier's original paper on CVA, Samprus was built to take into account the effects of netting and collateral on the bank's counterparty risk exposure. Roger explained that due to the resulting computational demands, Samprus was initially run on a room-sized SGI Origin supercomputer at the National Center for Supercomputing Applications in Urbana, Illinois, roughly 900 miles away from the bank's trading floor in New York City. At least once a week, the bank's entire trading database would be saved to a series of files, anonymized, and then transmitted to Urbana for analysis (Interview with Roger).

Yet the adoption of these Monte Carlo-based CVA methodologies tended to create additional tensions by limiting the agency of derivatives traders themselves. Indeed, in both the loan-equivalent and market-based approaches to CVA, when one models the effects of netting and collateral on the value of counterparty risk, CVA becomes a valuation that can only be defined at the level of individual counterparties rather than individual derivatives trades with those counterparties. This had an important organizational implication: CVA should be managed by a centralized group or trading desk, rather than by individual derivatives traders themselves, an arrangement that both Goldman Sachs and J.P. Morgan adopted. Yet the centralization of counterparty risk management effectively limited the agency of derivatives traders by constraining their ability to take credit risks with their bank's money and thus make larger profits. According to Matthew, conflicts over CVA were particularly acute at Goldman Sachs for this reason. Goldman's commodities division, which the firm inherited when it purchased J. Aron \& Company in 1981, did a considerable quantity of swaps business with low-rated counterparties. Goldman's commodities traders were initially permitted to book all of the earnings from those trades as profit. As Matthew explained, "the traders understood clearly that there was a huge amount of credit risk and that's why they were making money". In his view, Goldman's commodities traders believed that managing credit risk was a part of their responsibility. "They were thinking, 'Well, I'm a good credit manager too. When I run my commodities business, I choose my counterparties, I know where I'm going, and so I should be paid for that credit'.” As he noted, the establishment of a counterparty risk desk had the effect of limiting the types of risks that these traders were permitted to take:

The moment that you put a CVA in the mark-to-market - well, now the money doesn't belong to the trader anymore in terms of his skill, it belongs to the firm. The firm is taking credit risk and it's charging this thing and it's not being counted as P\&L of the trader anymore (Interview with Matthew). 
The diversity of CVA practices also created a tension throughout the broader market field arising from the evaluative dissonance between the various incarnations of CVA. Valuations of counterparty risk that use probabilities of default derived from historical data tend to be lower than those in which these probabilities are derived from market prices. This is due to the fact that in addition to being an indicator of default risk, the price of a company's bonds - or equivalently, the quoted 'spread' of a credit default swap written on those bonds - will also reflect the degree of risk aversion of bond investors. Due to the presence of this 'risk premium', market-implied probabilities of default usually tend to be higher than those derived from historical data. This, of course, meant that banks that adopted historical CVA practices could generally offer more attractive prices to their clients than those who used market-based CVA. In addition to generally implying a higher risk of default, market-based CVA was also considerably more volatile. When a commercial bank such as Citi reserved a portion of a trader's profit to cover potential future credit risk, the size of this reserve was unlikely to change over time, due to the fact that its size was determined using longterm historical data on default. At banks such as J.P. Morgan and Goldman Sachs, by contrast, this value could fluctuate on a day-to-day basis, in some cases in a highly volatile manner, due to changes in the market-implied credit risk of the counterparty. To protect themselves against these risks, banks that adopted market-based CVA would have to pay to hedge these risks.

In addition to dissonance arising between historical and market-based approaches to CVA, there was also dissonance among 'bilateral' and 'unilateral' approaches to market-based CVA. Bilateral market-based CVA generally provides the smallest possible downward adjustment to the value of a derivative, because a bank's derivatives liabilities are adjusted downward along with its assets to reflect the credit risk of the bank making the adjustment. This had a definite appeal to derivatives traders: a bilateral CVA would ensure that a trader would be able to offer prices very close to the mid-market price when the two counterparties had roughly equivalent credit ratings. Proponents of this approach could point to the fact that unlike loans, swaps and other OTC derivatives generally entail credit risk for both counterparties, and thus their value must in theory be sensitive to the default risk of both. Moreover, unless a bank has no risk of default, a bilateral CVA is theoretically necessary for the bank and its counterparty to be able to agree on a single valuation for a derivative. Suppose, for instance, an interest rate swap had a default-free value of $\$ 100$. If given the default risk of the counterparty, the bank were to calculate the value of its unilateral CVA to be $\$ 5$, then the value of the swap from the bank's perspective would be $\$ 95$. Using the same technique, the counterparty might calculate the default risk of the bank itself to be $\$ 3$, giving the counterparty's value of the swap as $-\$ 103$. For proponents of bilateral CVA, there is an unappealing asymmetry between these valuations that can only be corrected when both counterparties take the risk of default of both parties into account. In this case, the two parties to the swap would see its value as $\$ 98$ and $\$ 98$ respectively. Bryan, who helped develop CVA at Goldman Sachs, explained in an interview that 'if you mark-to-market, there 
can only be one price. You can't have your competitor just marking your credit, and you just marking theirs, and have two different prices. It doesn't make sense'.

On the other hand, the practice of valuing CVA in a bilateral fashion has strange implications. First, it has the unintuitive - and some would say perverse - benefit of allowing a bank to profit from a decrease in its own credit quality. Indeed, if a bank's own market-implied probability of default were to increase, this would translate into a reduction in the bank's overall CVA. Moreover, using the bilateral CVA technique it is theoretically possible for a derivative to have a negative CVA, which would imply that a derivative with counterparty risk is worth more than a derivative that is free from default risk (Gregory 2009). Moreover, a bilateral CVA is extremely difficult to fully replicate or hedge in line with the theoretical precepts of the Black-Scholes model and the broader culture of no arbitrage modelling. While a bank could hedge the risk of counterparty default by short selling its counterparty's corporate bonds or buying credit derivatives protection on that counterparty, to hedge the risk of its own default it would theoretically need to sell credit protection on itself, something that is not legally possible. To replicate bilateral CVA, then, banks must sell credit protection on other banks that have a high degree of correlation to themselves. But this has a serious downside, as Eugene - a counterparty risk quant - explained in an interview: 'if you're selling protection on another bank, then it's equivalent to banks wanting to buy each others' debt. And, you don't want banks holding lots and lots of each other's debt because that just makes them more interconnected' (Interview with Eugene).

As a consequence, at J.P. Morgan and many other banks, bilateral market-based CVA gained a reputation as being akin to 'accounting voodoo' rather than a justifiable valuation practice. In contrast to Goldman, JP Morgan instead became one of the strongest proponents of 'unilateral' market-based CVA, in which only the credit risk of its counterparties is priced. In fact, several former employees of J.P. Morgan that I interviewed viewed bilateral CVA with suspicion, given that the use of bilateral CVA almost always favors the bank's traders, since it allows the bank to charge them less for their counterparty risk. To some extent this choice may reflect J.P. Morgan's own historical origin as a commercial bank: While the practice of charging a CVA to a trader is roughly analogous to the older commercial bank practice of holding a portion of a loan's value in a loan-loss reserve (and indeed, seems to have evolved out of this reserving practice within J.P. Morgan), the concept of bilateral CVA has no such analogy in traditional commercial banking practice, given that loans are only ever classified as assets. On this point, Matthew explained in an interview that 'the guys in the [commercial] banks were treating CVA more like a reserve', and so the concept of [a bilateral] CVA seemed more foreign to them' (Interview with Matthew). 


\section{The Institutionalization of Market-Based CVA}

While financial economics and much of the existing social studies of finance literature suggests that evaluative disagreements tend to be resolved through a process of arbitrage, doing so was difficult if not impossible for banks in the case of CVA. This was due not only to the initial difficulty in hedging credit risk prior to the development of credit derivatives, but also to the fact that the value of CVA is tied to the credit worthiness of the bank's counterparty itself. Thus, there was no straightforward way for another market participant - such as another bank or hedge fund - to arbitrage a bank failing to value to value CVA appropriately, as Eugene explained in an interview:

Eugene: So, in normal derivatives markets, you know if you're super advanced, you can always try and essentially backdoor people and you know, arb them. In CVA you can't because, you know, if Citigroup is charging all of their clients less than me, I can't find any way to arb Citigroup, because they're just being idiots -

Author: They're being idiots; it's not just, yeah -

Eugene: Yeah, it's like having two insurance companies; one car insurance company is selling insurance really cheaply. And you're sitting there saying, "The only thing we can do is just wait for them to fail. We will keep doing the right thing, and presumably in a few years time they will go bankrupt or something because they are so idiotic, or change their practice and be a lot more conservative. But there's absolutely nothing I can do now".

Nor could these disagreements be resolved through a straightforward appeal to financial theory. Indeed, while market-based CVA was theoretically grounded in the Black-Scholes logic familiar to derivatives traders and quants, there were serious doubts - particularly in the late 1990s prior to the emergence of a market for credit derivatives - about the capacity of banks to actively hedge counterparty risk in line with the assumptions underlying the Black-Scholes model and arbitrage pricing theory more generally. Indeed, the fact that J.P. Morgan and Goldman Sachs were early adopters of market-based CVA was made possible by a crucial material detail: namely, the fact that both banks primarily dealt with prominent corporations and financial institutions that were large enough to either have issued their own bonds or have credit derivatives with which one could actively price and hedge the risk of their default. Sorensen and Bollier's CVA framework is, on its face, inapplicable in the absence of a set of prices from which one could extract a set of probabilities of default for the counterparty or hedge the resulting default risk. From this perspective, commercial banks using historical approaches to CVA relied upon the expert judgment of their credit officers not only as a matter of choice but also necessity.

Rather than through arbitrage, the institutionalization of market-based CVA came about through three interrelated sets of actions on the part of J.P. Morgan, Goldman Sachs, and other dealers who were in favor of these techniques. First, these dealers sought to legitimize the practice of explicitly valuing counterparty risk through their influence as elite actors within the field. Second, these banks sought to build sufficient liquidity in the credit derivatives markets by promoting their use and seeking bank capital exemptions when 
counterparty risk is hedged using these derivatives. Finally, these banks supported developments in adjacent fields - most notably, in the fields of tax and financial accounting - that supported the use of these practices. As a result of these institutional changes, firms in the derivatives markets encountered normative, coercive, and mimetic isomorphic pressures to adopt market-based CVA and its related practices and infrastructures.

In line with existing theories of institutional change, these processes were put into motion by a series of external shocks to the field itself: in this case, to the perceived safety and legitimacy of the derivatives markets by outside audiences, including regulators. The first of these shocks came in the mid-1990s, following a series of controversial derivatives-related losses. In 1994, Gibson Greetings - an Ohio-based greeting card company - sued Banker's Trust for misstating the value of a series of interest rate swaps that had been sold to the company. In the same year, Orange County in California declared bankruptcy after its Treasurer had purchased a series of leveraged floating rate bonds that lost their value after the US Federal Reserve chose to raise interest rates. In response to these events, financial regulators became increasingly interested in regulating the now large OTC derivatives market. During this time, Brooksley Born, then chair of the US Commodities and Futures Trading Commission, famously sought to extend the agency's administrative jurisdiction from commodities and futures exchanges to the OTC derivatives as well. In response, J.P. Morgan, Goldman Sachs, and a number of other core dealers discursively framed the use of CVA and its associated practices and infrastructures as evidence that the industry is capable of selfgovernance. To this end, these dealers authored a number of joint reports encouraging the adoption of CVA practices among other participants in the field. For instance, in 1993 the Group of 30 - a prominent Washington, D.C.-based think tank led by Paul Volcker, the former Fed Chairman - commissioned a report on the over-the-counter derivatives markets in order to address concerns among regulators and policy makers (Group of Thirty 1993). The organization asked J.P. Morgan to lead the development of a report on the best practices for managing risk in these markets, and to conduct a survey of other banks and end-users of derivatives on the use of these practices across the industry. Among other things, the report recommended that market participants ensure that banks reflect the credit risk of their counterparties in their derivatives valuations. Moreover, to quantify derivatives credit risk, the final report encouraged banks and other market participants to adopt Monte Carlo simulation systems of the kind that had been developed by Citi (Group of Thirty 1993, 15).

A second set of shocks came in 1997-1998, first with the Asian Financial Crisis, followed a year later by the collapse of Long-Term Capital Management, a highly leveraged hedge fund that engaged in fixedincome arbitrage, and which was run by two of the developers of the Black-Scholes model. The Asian Financial Crisis led to the widespread default of many counterparties based in the region, which - according to Alan, who worked at a commercial bank called Banker's Trust at the time - drew attention to the need to 
actively value the counterparty risk embedded in OTC derivatives transactions. The collapse of LTCM, which ultimately required a joint bail-out with the Federal Reserve and a number of banks including J.P. Morgan and Goldman Sachs, drew further attention to the weakness of many banks' counterparty risk management practices. In response to these events, J.P. Morgan and Goldman Sachs co-chaired an industry working group known as the Counterparty Risk Management Policy Group (CRPMG), which was ultimately endorsed by Alan Greenspan, the then Chairman of the U.S. Federal Reserve, and Robert Rubin, a former CEO of Goldman Sachs and then current Secretary of the Treasury of the United States. Although the report was not specific with respect to which methods should be adopted, one of the report's major recommendations to financial institutions was to develop 'internal counterparty credit risk cost allocation and valuation practices' to incentivise banks' traders and risk managers to 'manage proactively their counterparty credit risks' (Counterparty Risk Management Policy Group 1999, 30).

In addition to these efforts to create normative isomorphic pressure to adopt CVA practices and infrastructures, J.P. Morgan actively sought to build up a liquid market for credit derivatives, which was a necessary material prerequisite for the widespread adoption of market-based CVA, particularly at commercial banks that traded with counterparties that did not issue their own bonds. To this end, Hancock's group at J.P. Morgan successfully convinced its regulators to grant capital relief for banks that used credit derivatives to hedge counterparty risk. In the US, that decision came in August 1996 when the Federal Reserve decided that banks could reduce the amount of regulatory capital held against a counterparty's credit risk if one could show that the risk was hedged using a credit derivative (Tett 2009, 57). A similar exemption was later included in the Basel II bank capital accords, which were published in 2004: Under these standards, banks were allowed to substitute the probability of default of the bank's counterparty with the probability of default of the credit derivative protection seller for the purposes of calculating bank capital. Thus, if a bank hedged a derivative that it had transacted with a relatively high risk corporation with a credit derivative sold by another large bank with a stronger credit rating, the bank could thereby achieve considerable capital relief under Basel II (Interview with Russell).

Because of these exemptions, banks and their derivatives traders throughout the industry faced a compelling incentive to support the adoption of market-based CVA: The use of this practice could allow traders to reduce the capital that would need to be provisioned to their derivatives portfolios, and thereby do more derivatives business than would be possible otherwise. Thom, a counterparty risk specialist was involved with the development of CVA at Barclays, saw this as one of the primary reasons that Barclays and other banks came to adopt these modelling techniques:

... partly because you would hit [exposure] limits very quickly and therefore be stopped from doing business, CVA was a way, I guess, to try and see if you could stretch those limits a bit. 
Because theoretically, if you could hedge your counterparty risk, then there should be no limits, because you could hedge every single piece of exposure you've got against a client. I mean, practically it doesn't work that way. But theoretically, it was a way of kind of doing more business. So it was partly defensive but partly offensive as well, and I think the offensive aspect was where more sophisticated banks got involved, and traders realized it was in their own self-interest to try and have these types of instruments being hedged (Interview with Thom).

As Thom suggested, the adoption of CVA was driven in part by 'offensive', rather than strictly 'defensive' reasons: If by setting up a CVA trading desk within the bank's front office one could achieve relief from bank capital requirements, then traders could also argue that they should no longer be subject to percounterparty exposure limits established by their banks' own credit departments. Consequently, a bank's derivatives traders would be free to do more business (and thus earn higher compensation) without breaching these limits.

While these developments encouraged banks to adopt market-based CVA techniques, another set of developments in two adjacent fields - that of financial and tax accounting - would lead the market to standardize on the bilateral formulation of market-based CVA that had first been developed by Sorensen and Bollier and was used by Goldman Sachs. The first of these was a growing consensus among financial accounting standards bodies that financial reporting should be practiced on a 'fair value' basis, in which assets and liabilities are recorded at the best estimate of their current market value, instead of their historical costs. In the US, the Financial Accounting Standards Board (FASB) had worked throughout the 1990s to reconstruct accounting practices for many financial instruments on such a fair value basis. As has been noted in the accounting literature, a major impetus for this switch was the problem of accounting for derivatives: Because many OTC derivatives such as swaps have close to zero value at inception, banks were initially able to keep most of their derivatives assets and liabilities effectively 'off-balance sheet' under the older historical cost accounting regime. The FASB's desire to account for derivatives on a fair value basis was thus practically motivated by the same problem that had convinced the BCBS to include the credit risk of derivatives in bank capital requirements beginning with Basel I. Yet while the BCBS had effectively reified commercial banks' own practices for managing derivatives credit risk into bank capital standards, the FASB's decisions would instead come to mandate the practice of pricing CVA, and in particular, a bilateral market-based CVA.

The switch to fair value came in several stages. In 1991, the FASB published SFAS 107, which required banks to make footnote disclosures about the fair value of swaps and other derivatives, while SFAS No. 133, which went into effect in 1998, required that derivatives be reported at fair value on banks' balance sheets. As Morley (2014) notes, the FASB encountered intensive lobbying from many banks, many of which resisted SFAS 133 due to their concerns that being forced to report the fair value of their then offsheet derivatives exposures would force them to incur large losses. It was only after the Asian Financial 
Crisis in 1997 that the FASB was able to succeed in gaining sufficient political support to pass the new standard. However, while SFAS 133 required banks to report their derivatives assets and liabilities at fair value, the standard left open the technical definition of 'fair value' itself and how it ought to be measured. As a consequence, in the years following the passage of SFAS 133, there remained considerable variation in banks' own practices for valuing and managing counterparty risk.

To address these questions related to the measurement of fair value, the FASB released a new Statement of Financial Accounting Concepts in 2000 on the subject of accounting measurements (SFAC No. 7). The new conceptual document, which makes reference to the Black-Scholes model and other techniques from financial economics (Financial Accounting Standards Board 2000, 23), noted three crucially important features of the FASB's new emerging approach to fair value. First, as the FASB itself explained in a newsletter to its constituents, SFAC 7 grounds the notion of fair value measurement in the probabilistic notion of 'expected value', in contrast to the more traditional notion of 'best estimate' (Financial Accounting Standards Board 2001). In doing so, SFAC 7 aligned itself closely with theories of value from financial economics and the no arbitrage modelling practices preferred by investment banks, in which prices are seen as representing the discounted expected value of an asset's future payoff. Second, it declared that 'an estimate of fair value should include the price that marketplace participants are able to receive for bearing the uncertainties in cash flows - the adjustment for risk - if the amount is identifiable, measurable, and significant' (Financial Accounting Standards Board 2000, 62). In other words, all sources of risk affecting the value of financial instruments such as derivatives should be reflected in that instrument's fair value estimate insofar as that risk is significant and can be measured. In the case of counterparty risk, the FASB's concept statement implied that banks would be required to explicitly price this risk in the form of a CVA and reflect changes in its value through the income statement. Third, the conceptual document declared that both assets and liabilities should be measured at fair value (Financial Accounting Standards Board 2000, 75). Thus in the case of counterparty risk, the conceptual framework suggested that banks would need to not only calculate a CVA, but a bilateral CVA of the type preferred by Goldman Sachs.

Consensus in favor of the bilateral approach to CVA was further established by a major court ruling related to tax accounting. As banks began to adopt CVA pricing techniques throughout the 1990s, they began to incorporate CVA into their income tax reporting process, a change that received significant scrutiny from the US Internal Revenue Service (IRS). In a landmark tax case that was decided in 2003, the U.S. Tax Court determined that the First National Bank of Chicago (FNBC) - a U.S. commercial bank and swaps dealer had misrepresented the fair market value of its swaps for tax purposes during the early 1990s by applying 
an improper valuation methodology to account for its counterparty risk. ${ }^{9}$ As the Court's opinion describes, FNBC had applied a historical Monte Carlo-based 'peak exposure' calculation system to calculate a credit valuation adjustment to its reported swaps income for tax purposes, of the kind discussed in section 6 . The bank was taken to court by the IRS, which argued that by doing so, it had understated the tax liability owed on its derivatives. (A swap's 'peak exposure' will generally be much higher than its 'expected exposure', which forms the basis of typical CVA calculations.) One of the Court's expert witnesses was Darrell Duffie, the financial economist who had generalized Sorensen and Bollier's bilateral counterparty risk framework, and who had consulted with Morgan Stanley and Goldman Sachs on counterparty risk valuation in the early 1990s. In his expert testimony, Duffie noted that FNBC's peak-exposure system would understate the fair market value of FNBC's swaps, in part because it failed to take into account the bilateral nature of counterparty risk (Duffie 2001). The Court ultimately sided with Duffie's recommendation that for tax purposes, credit risk adjustments 'should reflect the credit quality of both parties' to a derivative transaction, in line with the bilateral approach to CVA (Kawaller and Guyader 2003).

Thus when the FASB released a draft of SFAS 157 in 2004 - the accounting standard that would formalize SFAC 7 into US generally accepted accounting practices (GAAP) - there was a growing consensus within the accounting community that fair value measurements should include adjustments to both the asset and liabilities side of the balance sheet to account for the value of credit risk. Indeed, SFAS 157 further clarified that fair value estimates must reflect the risk of 'non-performance', including the reporting entity's own credit risk, leaving little doubt that only the bilateral formulation of CVA would be compatible with the draft accounting standard. SFAS 157 also included an additional requirement: banks and other financial institutions must use market prices, rather than historical information, to calculate these adjustments when doing so is possible. This latter requirement implicitly mandated that models used to calculate a bank's CVA be calibrated directly to observable market prices, in line with the techniques used by derivatives traders and other practitioners of the culture of no arbitrage modelling.

A handful of large dealer banks - among them Citibank, JP Morgan, and Goldman Sachs - played an active role in shaping the resulting debate over the new draft standard after its release in 2004. All three banks, for instance, submitted comment letters to the FASB in response to the draft standard, ${ }^{10}$ and representatives of all three participated in a series of FASB-sponsored roundtables designed to elicit industry views on the

\footnotetext{
${ }^{9}$ See: Bank One Corporation and Affiliated Corporations v. Commissioner of Internal Revenue, Nos. 5759-95, 5956-97 (U.S. Tax Court, May 2, 2003). See also Taylor and Worle (2008) for an overview of the case and the implications of the Court's ruling.

${ }^{10}$ Copies of comment letters from all three banks are available at: http://www.fasb.org/jsp/FASB/CommentLetter_C/CommentLetterPage\&cid=1218220137090\&project_id=1201-100.
} 
new draft. ${ }^{11}$ (Indeed, Blythe Masters, a prominent member of Hancock's team at J.P. Morgan who by then was the bank's Chief Financial Officer, was the bank's representative at one of these roundtables.) By that point, all three banks practiced CVA pricing in some form or another, and thus the question of whether fair value measurements should incorporate a credit adjustment at all was relatively uncontroversial. Yet in line with their own internal cultures of counterparty risk management, these banks were split on the question of whether the fair value of banks' liabilities should reflect their own risk of default. In particular, they sparred over the question of whether gains/losses from changes in one's own credit risk are 'realizable': that is, whether a bank could actually benefit from a gain in reported earnings from such a change, given the aforementioned difficulties involved in replicating or hedging a bilateral CVA. Goldman Sachs, for instance, enthusiastically supported the FASB's proposal and argued that such gains are realizable. JP Morgan, by contrast, noted that while it appreciated the theoretical arguments in favour of a symmetrical treatment of liabilities, the bank believed that any resulting gains and losses would be difficult - if not impossible - to realise. Citibank, reflecting its now mixed culture of practice following its acquisition of Salomon Brothers, was more ambivalent on the issue. Ultimately, despite push-back from Citibank and JP Morgan, the FASB ultimately chose to require a bilateral credit risk adjustment in the final version of SFAS 157. The IASB later implemented the content of SFAS 157, nearly word-for-word, into IFRS reporting standards via IFRS 13 in 2011 (International Accounting Standards Board 2011), as a part of the IASB's own convergence project.

The timing of the implementation of SFAS 157 in 2007 however proved to be unfortunate: In the years leading up to the 2008 financial crisis, a set of specialist insurance firms known as 'monoline' insurers had sold the large banks that make up the core of the financial system billions of dollars in credit derivatives protection to insure them against defaults arising from asset-backed securities and other instruments containing mortgages (c.f. MacKenzie 2011). Throughout 2007 and 2008, banks' credit exposure to these derivatives increased just as the market-implied probabilities of default of these insurers spiked, thereby causing a multiplicative increase in the CVA of these instruments, a dreaded phenomenon known among counterparty risk quants as 'wrong-way risk' (Murphy 2009, 231). While all banks subject to US GAAP were now required to report changes in market-based CVA as gains and losses in their financial statements, relatively few had set-up counterparty risk trading desks of the sort that had long been in place at Goldman

\footnotetext{
${ }^{11}$ See: FASB Fair Value Measurement Team, 'Minutes of the September 21, 2004 FVM Public Roundtable', Available at: http://www.fasb.org/jsp/FASB/Document_C/DocumentPage\&cid=1218220111989 and http://www.fasb.org/jsp/FASB/Document_C/DocumentPage\&cid=1218220111961.
} 
Sachs and J.P. Morgan in order to hedge this resulting earnings volatility. ${ }^{12}$ As Matthew, a counterparty risk practitioner who had helped develop CVA at Goldman, remarked in an interview:

What made the commercial banks switch was not because they bought into the idea; it was because the accounting rules forced them to buy into the idea. And they bought into the idea without believing the idea. [...] They started marking-to-market, but they still were not hedging (Interview with Matthew).

Thus, as the market-implied CVA associated with this mortgage default protection spiked, many large banks in the U.S. were forced to report the billions of dollars of fair value losses mentioned in the introduction of this paper.

Since the crisis, market-based CVA has become more institutionalized within the fabric of the financial markets; however, the material underpinnings of these techniques have been eroded by a substantial decline in liquidity in the credit derivatives markets. The losses that various American banks suffered vindicated the practice of actively hedging CVA, given the effect that ignoring this risk can have on a bank's earnings volatility under fair value accounting practices. Establishing a CVA trading desk to hedge these fair value gains and losses thus quickly became framed as a 'best practice' of bank risk management; Indeed, since the crisis, the adoption of this practice has spread rapidly, even to the periphery of the derivatives field, much in line with classic institutionalist depictions of practice adoption (Tolbert and Zucker 1983). Following 2008, there was a sharp increase in hiring of quants and traders with a background in CVA pricing and trading among US and European banks. Chris Kenyon and Roland Stamm, two prominent counterparty risk quants, note in a recent book on the subject that ' $[t]$ he biggest growth areas for quant employment over the period 2010-2012 has been in counterparty risk and on CVA desks. Five years ago, few banks had dedicated CVA desks; today it would be hard to find any significant bank without one' (Kenyon and Stamm 2012, 182). Global bank regulators have also, not surprisingly, responded to the financial crisis by incorporating new capital requirements to cover changes in the fair value of CVA into the Basel III bank capital standards (Basel Committee on Banking Supervision 2011, 2010:3).

However, even as the use of market-based CVA has become further institutionalized within global finance, its status among traders, quants and other practitioners of the culture of no arbitrage modelling has remained contentious. While market-based CVA was indeed originally a product of that culture, the fact that the bilateral version of market-based CVA is not only difficult to fully hedge or replicate in line with the practices of no arbitrage modelling but is now a fundamental component of fair value accounting has led

\footnotetext{
${ }^{12}$ Bank of America is an example of an American bank that suffered considerable CVA-related losses in the midst of the crisis. The bank's 2007 annual report reports that the bank incurred \$200 million in losses on insurance the bank had purchased from monoline insurers that was due to adjustments to fair value arising from counterparty credit risk (Bank of America 2007, 55).
} 
some CVA practitioners to see it as 'accounting voodoo' (Carver 2012). Adding to this problem is the fact that the material conditions of the financial markets have become increasingly misaligned with the assumption of market completeness underlying the approaches to valuing CVA that are implicitly mandated by SFAS 157 and now IFRS 13. Indeed, since the failure of the monoline insurance firms during the financial crisis, the credit derivatives markets have lacked participants willing to sell credit default protection on all but a relatively small number of counterparties. As a consequence, the liquidity of the market for credit derivatives, the growth of which played a crucial role in allowing market-based CVA and related practices to spread initially, has declined substantially since the crisis. A 2011 study by the Federal

Reserve Bank of New York, for example, found that trading became rare in these markets following the crisis, particularly within the category of 'single-named' credit default swaps (CDS), which can be used to specifically hedge the default risk of a particular counterparty (Chen et al. 2011). Even today, despite efforts by some in the industry to jumpstart trading in these markets, single-named CDS contracts remain particularly illiquid (Ahmed and Natarajan 2017). The most active trading in CDS, by contrast, is in a set of instruments known as 'CDS indices', whjch give the buyer default protection on a large basket of companies, but cannot provide default protection against any particular company within the basket. Thus in this environment, banks have been forced to make a rather procrustean set of modelling choices to fulfil their requirements to value CVA: Given that they are unable to reliably 'back out' probabilities of default from single-name CDS contracts associated with each individual counterparty, many banks have come to rely on 'proxy spreads' to determine these probabilities. This approach, which is now enshrined within Basel III, involves inferring these unobserved spreads from the quoted spreads of companies that are classified as similar to the company in question (e.g. competing firms within the same industry, or companies with similar credit ratings), or inferring this information from a major CDS index (Kenyon and Stamm 2012, 193; Basel Committee on Banking Supervision 2015). Several interviewees explained to me that because liquidity in these markets has declined, it has become exceptionally difficult to price CVA in line with the theoretical precepts of the culture of no-arbitrage modelling, the evaluation culture from which market-based CVA emerged. Simon, a quant who oversees CVA at a major London bank, explained in an interview: 'I got asked at a conference, 'Do you believe in CVA?' And I said, '[Only] to a degree. Because you can't hedge it - you can't hedge all of it' (Interview with Simon).

\section{Conclusion}

While the causes of the switch to fair value accounting by the major accounting standards boards have begun to attract attention in recent years from accounting scholars, with some exceptions (c.f. Lins, Servaes, and Tamayo 2011), there has been relatively little work examining how the switch to fair value has in turn altered the valuation practices used by financial market participants, particularly in the derivatives markets 
where the requirements to practice fair value accounting are perhaps most stringent. This may reflect an implicit assumption within the existing literature that when the FASB adopted fair value accounting for derivatives in late 1990 s and early 2000 s, it merely legitimized a set of valuation practices drawn from financial economics for which derivatives market practitioners had already achieved a relatively uniform consensus in favour of using. Power (2010) and Morley (2014), for instance, both point to the problem of accounting for derivatives as a catalyst for the broader adoption of fair value by the FASB in fields where these techniques were much more controversial, and how the Black-Scholes model had become dominant among derivatives market practitioners at the time of fair value's adoption. As such, the existing literature implicitly assumes that the adoption of fair value in the case of derivatives did not fundamentally alter how derivatives market practitioners themselves approached the valuation of derivatives.

In this paper, I have examined the relationship between the switch to fair value and the development and adoption of a set of financial modelling practices and infrastructures that banks use to assign a value known as a 'credit valuation adjustment' (CVA) - to the counterparty risk associated with derivatives they trade on an 'over-the-counter' basis. Counterparty risk, as we saw, is a hybrid of market risk and credit risk. While the Black-Scholes model and its intellectual descendants quickly became established as dominant techniques for managing the market risk of derivatives even prior to the adoption of fair value, banks formed no such consensus over the management of the credit risk component. Instead, banks developed two broad approaches to the valuation of derivatives credit risk that were grounded in distinct institutional logics of risk management. Most commercial banks came to see derivatives credit risk as an extension of the credit risk of commercial loans; they thus sought to calculate CVA using actuarial principles by developing models capable of commensurating between the credit risk of these two types of assets, which allowed them to embed the management of derivatives credit risk within their existing risk management infrastructure. At a small group of investment banks led by J.P. Morgan and Goldman Sachs, however, practitioners with strong ties to the discipline of financial economics developed a set of practices and infrastructures that extended the market-oriented logic of the Black-Scholes model to the valuation and management of derivatives credit risk, with its focus on risk management through marking-to-market and hedging. These practices included new forms of organization; in contrast to most commercial banks, both Goldman Sachs and J.P. Morgan developed specialized CVA trading desks to hedge counterparty risk created by the activities of the bank's other derivatives traders, and 'charge' these traders for the risks they took. We saw that the diversity of practices used by banks to manage counterparty risk engendered valuation conflicts that could not be resolved through market mechanisms, such as arbitrage. Instead, these investment banks came to use their institutional position within the broader field to legitimize the use of these market-oriented valuation practices. This included efforts to frame market-based CVA as a 'best practice' following a number of external shocks to the field, as well as attempts to lobby regulators to create capital exemptions 
for credit derivatives, the instruments that practitioners use to hedge market-based CVA. While these actions did encourage the adoption of market-based CVA, the FASB's adoption and formulation of fair value accounting - which these dealers actively sought to influence - ultimately came to 'tip the balance' in favor of these dealers' preferred valuation practices.

Did the adoption of fair value by the FASB merely institutionalize a preference for valuation techniques drawn from financial economics that had already become a matter of consensus among market practitioners? Despite fair value accounting's ambition to 'faithfully represent' economic reality, at least in the case of counterparty risk the answer is no: fair value instead seems to have played an active role in encouraging the adoption of a particular method of measuring CVA - that was preferred by Goldman Sachs in particular - and the organizational and risk management practices associated with it. The financial crisis demonstrated to derivatives market practitioners the dangers of leaving CVA unhedged when changes in its value must be reported as gains and losses in income in accordance with fair value accounting. Since the crisis, adoption of the risk management techniques first developed by Goldman and J.P. Morgan accelerated throughout the derivatives market field, even as the material conditions of the financial markets have become increasingly misaligned with this technique of managing counterparty risk. Market-based CVA, while in many ways a product of financial economics and the culture of no-arbitrage modelling, now seems to be used primarily because of its institutionalization within regulatory and accounting rules, more so than for its technical merits as a method of quantifying and managing risk.

Both micro-level material details and meso-level institutional factors thus played a critical role in shaping how banks presently value and manage counterparty risk, in contrast to much of the existing empirical work on the development of new financial practices, which tends to emphasize one set of factors or the other. This paper's major methodological contribution is thus to sketch a hybrid approach to the study of financial practices that combines a focus on these two sets of factors.

\section{Acknowledgements}

I wish to thank my interviewees who were willing to share their personal experiences with the events discussed in this paper. I also wish to thank Celeste Berteau, Donald MacKenzie, Erica Coslor, Nathan Coombs, Arjen Van Der Heide, Yuval Millo, Shaul Hayoun, Maude Pare Plante, Ebba Sjögren, and other members of the faculty of the Stockholm School of Economics Accounting Department, as well as participants of the 'Constructing Financial Risk' workshop at the Cass Business School and the 'Valuation, Technology and Society' workshop for useful comments on earlier drafts of this paper. 


\section{Funding}

The research leading to these results was funded by the European Research Council under the European Union's Seventh Framework Programme (FP7, grant 291733). 


\section{References}

Ahmed, Nabila, and Sridhar Natarajan. 2017. "BlackRock's on a Mission to Save the Credit-Default Swaps Market.” https://www.bloomberg.com/news/articles/2015-05-05/blackrock-s-on-a-mission-tosave-the-credit-default-swaps-market.

Arrow, Kenneth J. 1964. "The Role of Securities in the Optimal Allocation of Risk-bearing." The Review of Economic Studies 31 (2): 91-96.

Ayache, Elie. 2007. "The Next Question Concerning Technology - Part 1: The Significance of Dynamic Replication.” Wilmott Magazine, 32-38.

Bank of America. 2007. “2007 Annual Report.”

Bank of England. 1987. "Potential credit exposure on interest rate and foreign exchange rate instruments." London: Bank of England.

Barnes, Barry, David Bloor, and John Henry. 1996. Scientific Knowledge: a Sociological Analysis. Vol. 30. London: Athlone Press. doi:10.1016/S0898-1221(96)90253-9.

Basel Committee on Banking Supervision. 2009. "Consultative Document: Strengthening the resilience of the banking sector.” December 2009. Basel, Switzerland: Bank for International Settlements.

Vol. 2010. June.

—. 2015. "Review of the Credit Valuation Adjustment Risk Framework." Bank of International Settlements.

Beunza, Daniel, and David Stark. 2012. "From Dissonance to Resonance: Cognitive Interdependence in Quantitative Finance." Economy and Society 41 (3): 383-417.

Bond, Ian, Gareth Murphy, and Gary Robinson. 1994. "Potential Credit Exposure on Interest Rate Swaps." London: Bank of England.

Brown, Keith C, and Donald J Smith. 1993. "Default risk and innovations in the design of interest rate swaps." FM: The Journal of the Financial Management Association 22: 94.

Canabarro, Eduardo, Evan Picoult, and Tom Wilde. 2003. "Analyzing Counterparty risk.” Risk Magazine, no. September: $117-22$.

Carberry, Edward J., and Brayden G. King. 2012. "Defensive Practice Adoption in the Face of Organizational Stigma: Impression Management and the Diffusion of Stock Option Expensing." Journal of Management Studies 49 (7): 1137-67. doi:10.1111/j.1467-6486.2012.01075.x.

Carver, Laurie. 2012. "Show me the money." Risk Magazine, no. March: 30-33.

Cesari, Giovanni, John Aquilina, Niels Charpillon, Zlatko Filipovic, Gordon Lee, and Ion Manda. 2009. Modelling, Pricing, and Hedging Counterparty Credit Exposure: A Technical Guide. Springer-Verlag Berlin Heidelberg.

Chen, Kathryn, Michael Fleming, John Jackson, Ada Li, and Asani Sarkar. 2011. "Federal Reserve Bank of New York Staff Reports An Analysis of CDS Transactions : Implications for Public Reporting." Federal Reserve Bank of New York Staff Reports. 
Compagni, Amelia, Valentina Mele, and Davide Ravasi. 2015. "How early implementations influence later adoptions of innovation: Social positioning and skill reproduction in the diffusion of robotic surgery." Academy of Management Journal 58 (1): 242-78. doi:10.5465/amj.2011.1184.

Cooper, Ronald. 1987. "Swap houses switch to new rules." Euromoney Magazine, no. January (January): $32-33$.

Counterparty Risk Management Policy Group. 1999. "Improving Counterparty Risk Management.” June.

Davis, Gerald F, and Mark S Mizruchi. 1999. "The Money Cannot Hold: Commercial Banks in the U.S. System of Corporate Governance.” Administrative Science Quarterly 44: 215-39.

DiMaggio, PJ, and WW Powell. 1983. "The iron cage revisited: Institutional isomorphism and collective rationality in organizational fields." American Sociological Review 48 (2): 147-60.

http://www.jstor.org/stable/10.2307/2095101.

Donaldson, T.H. 1983. Understanding corporate credit: the lending banker's viewpoint. London: MacMillan.

1989. Credit risk and exposure in securitization and transactions. Houndmills, Basingstoke, Hampshire: MacMillan Press Ltd.

Duffie, D, and Ming Huang. 1996. "Swap Rates and Credit Quality.” The Journal of Finance 51 (3).

Duffie, Darrell. 2001. "Expert Report of Darrell Duffie, Bank One Corporation and Affiliated Corporations v. Commissioner of Internal Revenue."

Duffie, Darrell, and Kenneth J. Singleton. 2003. Credit Risk: Pricing, Measurement, and Management. Princeton University Press.

Engelen, Ewald, Ismail Erturk, Julie Froud, Adam Leaver, and Karel Williams. 2010. "Reconceptualizing financial innovation: Frame, conjuncture and bricolage." Economy and Society 39 (1): 33-63. doi:10.1080/03085140903424568.

Erb, Carsten, and Christoph Pelger. 2015. “Twisting words'? A study of the construction and reconstruction of reliability in financial reporting standard-setting." Accounting, Organizations and Society 40 (0): 13-40. doi:10.1016/j.aos.2014.11.001.

Financial Accounting Standards Board. 2000. "SFAC No. 7 - Using Cash Flow Information and Present Value in Accounting Measurements."

http://www.fasb.org/jsp/FASB/Document\{\_\}C/DocumentPage?cid=1218220132570.

—. 2001. "Expected Cash Flows." Understanding the Issues 1 (1): 1-19.

doi:10.1002/9781118720011.ch1.

2006. "Statement of Financial Accounting Standards No. 157: Fair Value Measurements." No. 284-A. Norwalk: Financial Accounting Standards Board.

Flanagan, Sean M. 2001. "The Rise of a Trade Association: Group Interactions Within the International Swaps and Derivatives Association." Harvard Negotiation Law Review 6: 211-64.

Fligstein, Neil, and Luke Dauter. 2007. "The Sociology of Markets." Annual Review of Sociology 33 (1): 105-28. doi:10.1146/annurev.soc.33.040406.131736.

Fligstein, Neil, and Doug McAdam. 2012. A Theory of Fields. Oxford: Oxford University Press. 
Funk, Russell J, and Daniel Hirschman. 2014. "Derivatives and Deregulation : Financial Innovation and the Demise of Glass - Steagall." Administrative Science Quarterly 59: 669-704.

doi:10.1177/0001839214554830.

Greenwood, Royston, Roy Suddaby, and C. R. Hinings. 2002. "Theorizing Change: The Role of Professional Associations in the Transformation of Institutionalized Fields." Academy of Management 45 (1): 58-80.

Gregory, Jon. 2009. "Being two-faced over counterparty credit risk.” Risk Magazine 22 (2): 86-90.

- 2010. Counterparty Credit Risk and Credit Valuation Adjustment: A Continuing Challenge for Global Financial Markets. John Wiley; Sons.

Group of Thirty. 1993. "Derivatives: Practices and Principles.” Washington, D.C.

Hansell, Saul. 1991. “The Risk Collectors.” Institutional Investor 25 (10): 57-65.

Harrison, J.M., and S.R. Pliska. 1983. "A stochastic calculus model of continuous trading: complete markets." Stochastic Processes and Their Applications 15 (3). Elsevier: 313-16.

Henderson, Schuyler K. 1989. "Swap Credit Risk: A Multi-Perspective Analysis.” The Business Lawyer 44 (2): $365-400$.

Henderson, Schuyler K. 1983. "Credit Risk and Swap Exposure.” In Swap Financing Techniques, edited by Boris Antl, 115-23. London: Euromoney Publications.

International Accounting Standards Board. 2011. "IFRS 13: Fair Value Measurement." IFRS Foundation.

Kawaller, Ira, and Lou Le Guyader. 2003. “The Bank One swaps market precedent.” Risk Magazine, no. November: 56-58.

Kenyon, Chris, and Roland Stamm. 2012. Discounting, Libor, CVA and Funding: Interest Rate and Credit Pricing. Palgrave Macmillan.

Knorr-Cetina, Karin. 2000. Epistemic Cultures: How the Sciences Make Knowledge. Harvard University Press.

Lawrence, David. 1995. "Aggregating Credit Exposures: The Simulation Approach.” In Derivative Credit Risk: Advances in Measurement and Management, edited by Robert Jameson, 23-31. London, UK: Risk Publications.

Lins, Karl V, Henri Servaes, and Ane Tamayo. 2011. "Does Fair Value Reporting Affect Risk Management? International Survey Evidence." Financial Management 40 (3): 525-51.

doi:10.1111/j.1755-053X.2011.01152.x.

Lounsbury, Michael. 2002. "Institutional Transformation And Status Mobility: The Professionalization of the Field of Finance." Academy of Management Journal 45 (1): 255-66. doi:10.2307/3069295.

MacKenzie, D., and T. Spears. 2014. “'The formula that killed Wall Street': The Gaussian copula and modelling practices in investment banking." Social Studies of Science 44 (3): 393-417.

doi:10.1177/0306312713517157.

MacKenzie, Donald. 2003. "Long-Term Capital Management and the Sociology of Arbitrage." Economy and Society 32 (3): 349. doi:10.1080/03085140303130. 
- 2009. "Ten precepts for the social studies of finance." In Material Markets: How Economic Agents Are Constructed, edited by Donald Mackenzie, 8-37. Oxford University Press.

- 2011. "The Credit Crisis as a Problem in the Sociology of Knowledge." American Journal of Sociology 116 (6). University of Chicago PressChicago, IL: 1778-1841. doi:10.1086/659639.

Mackenzie, Donald. 2017. "Material Signals : A Historical Sociology of High- Frequency Trading." American Journal of Sociology, no. Forthcoming.

MacKenzie, Donald, and Yuval Millo. 2003. "Constructing a Market, Performing Theory: The Historical Sociology of a Financial Derivatives Exchange.” American Journal of Sociology 109 (1): 107-45. doi:10.1086/374404.

MacKenzie, Donald, and Juan Pablo Pardo-Guerra. 2014. "Insurgent capitalism: Island, bricolage and the re-making of finance." Economy and Society 5147 (May): 1-30. doi:10.1080/03085147.2014.881597.

MacKenzie, Donald, and Taylor Spears. 2014. “'A Device For Being Able to Book P\&L': The Organizational Embedding of the Gaussian Copula." Social Studies of Science 44: 418-40. doi: $10.1177 / 0306312713517158$.

Merton, Robert C. 1974. "On the Pricing of Corporate Debt: The Risk Structure of Interest Rates." Journal of Finance 29 (2): 449-70.

23-41.

Miller, Peter. 1994. "Accounting as social and institutional practice: an introduction." In Accounting as Social and Institutional Practice, edited by Anthony G. Hopwood and Peter Miller, 1-39. Cambridge: Cambridge University Press.

—. 1998. "The margins of accounting." European Accounting Review 7 (4): 605-21. doi:10.1080/096381898336213.

Miller, Peter, and Nikolas Rose. 1990. “Governing economic life.” Economy and Society 19 (1): 1-31. doi:10.1080/03085149000000001.

Miron, Paul, and Philip Swannell. 1991. Pricing and Hedging Swaps. Euromoney Publications.

Mirowski, Philip, and Edward Nik-Khah. 2008. "Command Performance: Exploring What STS Thinks It Takes to Build a Market.” In Living in a Material World: Economic Sociology Meets Science and Technology Studies, edited by Trevor Pinch and Richard Swedberg, 89-128. Cambridge, MA: MIT Press.

Modell, Sven, Eija Vinnari, and Kari Lukka. 2017. "On the virtues and vices of combining theories: The case of institutional and actor-network theories in accounting research." Accounting, Organizations and Society 60. Elsevier Ltd: 62-78. doi:10.1016/j.aos.2017.06.005.

Morley, Julia. 2014. "Sequences of Change in Financial Reporting: The Influence of Financial Economics.” London School of Economics; Political Science.

Murphy, David. 2009. Unravelling the Credit Crunch. 1st ed. Boca Raton: Chapman \& Hall/CRC.

Nijholt, J.J.a, P.-J.b Bezemer, and P.c Reinmoeller. 2016. "Following fashion: Visible progressiveness and the social construction of firm value." Strategic Organization 14 (3): 220-47.

doi:10.1177/1476127015617673. 
Power, Michael. 2010. "Fair value accounting, financial economics and the transformation of reliability." Accounting and Business Research 40 (3): 197-210. doi:10.1080/00014788.2010.9663394.

Rao, H., P. Monin, and R. Durand. 2005. "Border Crossing: Bricolage and the Erosion of Categorical Boundaries in French Gastronomy." American Sociological Review 70 (6): 968-91. doi:10.1177/000312240507000605.

Rebonato, Riccardo. 2004. Volatility and Correlation: the Perfect Hedger and the Fox. John Wiley; Sons.

Rowe, David M. 2003. “The Evolution of Counterparty Credit Risk Management.” In Modern Risk Management: A History, edited by Peter Field, 205-22. London, UK: Risk Books.

Saunders, Anthony, and Linda Allen. 2002. Credit Risk Measurement: New Approaches to Value at Risk and Other Paradigms. New York: John Wiley \& Sons.

Sorensen, E.H., and T.F. Bollier. 1994. "Pricing swap default risk.” Financial Analysts Journal 50 (3). JSTOR: $23-33$.

Taylor, John, and Kelly Worle. 2008. "Exploring the Accounting Method Implications of Bank One." Business Entities 10 (4): 28-56.

Tett, Gillian. 2009. Fool's Gold: How Unrestrained Greed Corrupted a Dream, Shattered Global Markets and Unleashed a Catastrophe. Little, Brown; Company.

Thornton, Patricia H., William Ocasio, and Michael Lounsbury. 2012. The Institutional Logics Perspective: A New Approach to Culture, Structure, and Process. Oxford: Oxford University Press.

Thornton, PH, and William Ocasio. 1999. "Institutional logics and the historical contingency of power in organizations: Executive succession in the higher education publishing industry, 1958-1990." American Journal of Sociology 105 (3): 801-43. http://www.jstor.org/stable/10.1086/210361.

Tolbert, Pamela S, and Lynne G Zucker. 1983. "Institutional Sources of Change in the Formal Structure of Organizations: The Diffusion of Civil Service Reform , 1880-1935." Administrative Science Quarterly 28 (1): 22-39.

Treacy, W F, and M Carey. 2000. "Credit risk rating systems at large US banks." Journal of Banking \& Finance 24 (1-2): 167-201. doi:10.1016/s0378-4266(99)00056-4.

UK Financial Services Authority. 2010. "The prudential regime for trading activities: a fundamental review." London, UK: UK Financial Services Authority.

http://www.fsa.gov.uk/pubs/discussion/dp10_04.pdf.

Vollmer, Hendrik, Andrea Mennicken, and Alex Preda. 2009. "Tracking the numbers: Across accounting and finance, organizations and markets." Accounting, Organizations and Society 34 (5): 619-37.

doi:10.1016/j.aos.2008.06.007.

Walter, John R. 1991. "Loan loss reserves." Economic Review of the Federal Reserve Bank of Richmond, no. July/August: 20-30.

Whittaker, J. Gregg. 1987. "Interest Rate Swaps: Risk and Regulation.” Federal Reserve Bank of Kansas City Economic Review, no. March: 3-13.

Wilmott, Paul. 2007. Paul Wilmott Introduces Quantitative Finance. John Wiley; Sons. 
Zigas, David. 1984. "Interest rate swaps popular, but credit quality problems remain." https://business.highbeam.com/392958/article-1G1-3471183/interest-rate-swaps-popular-but-creditquality-problems.

Zuckerman, Ezra W. 1999. "The Categorical Imperative: Securities Analysts and the Illegitimacy Discount.” American Journal of Sociology 104 (5): 1398-1438. 


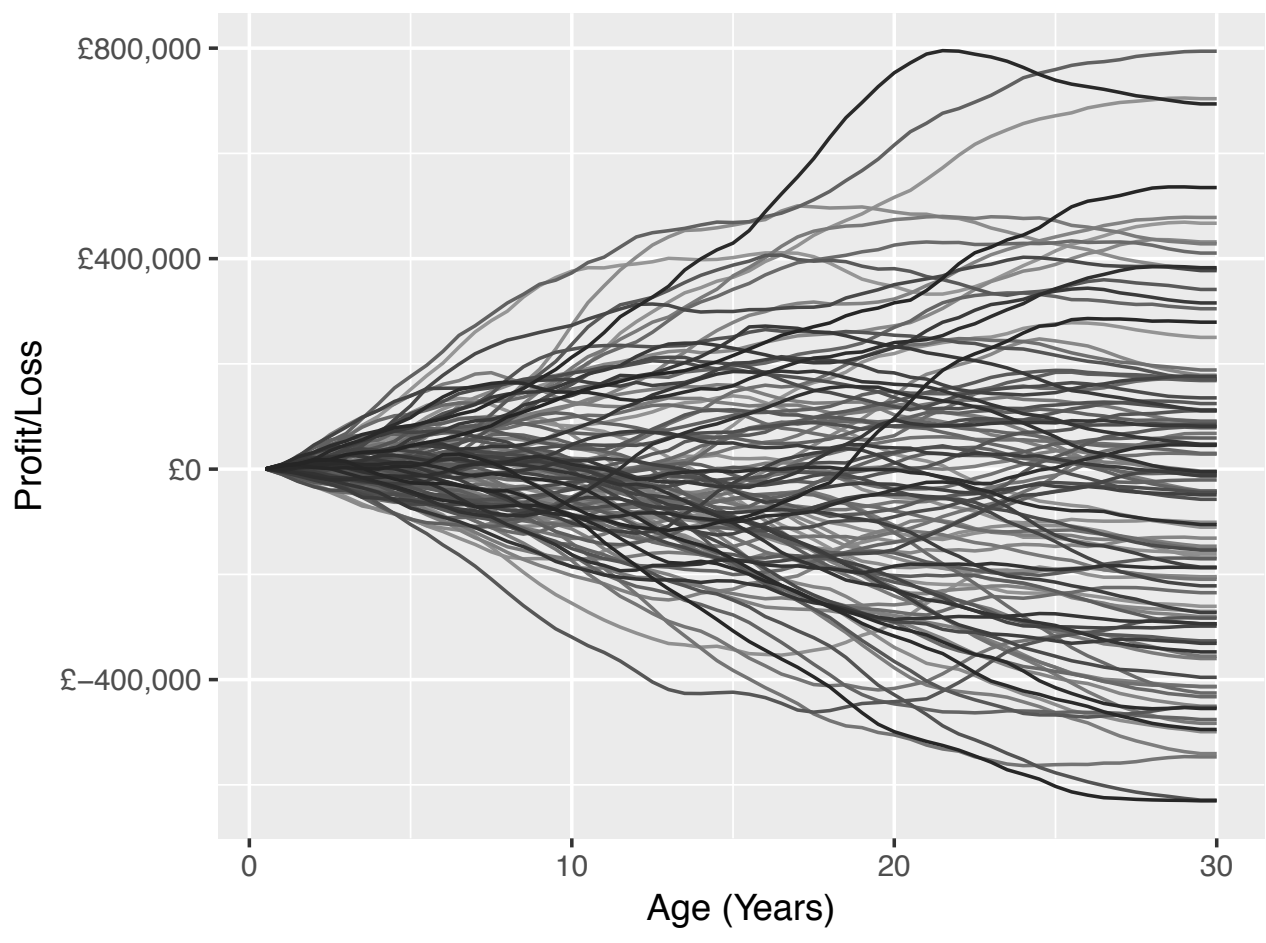

Figure 1: Simulated profit and loss scenarios of a fixed/floating interest rate swap, depending on changes in market interest rates. This figure was generated by simulating future interest rates using a one-factor Vasicek term structure model calibrated to historical data on changes in the value of US Treasury bonds. 


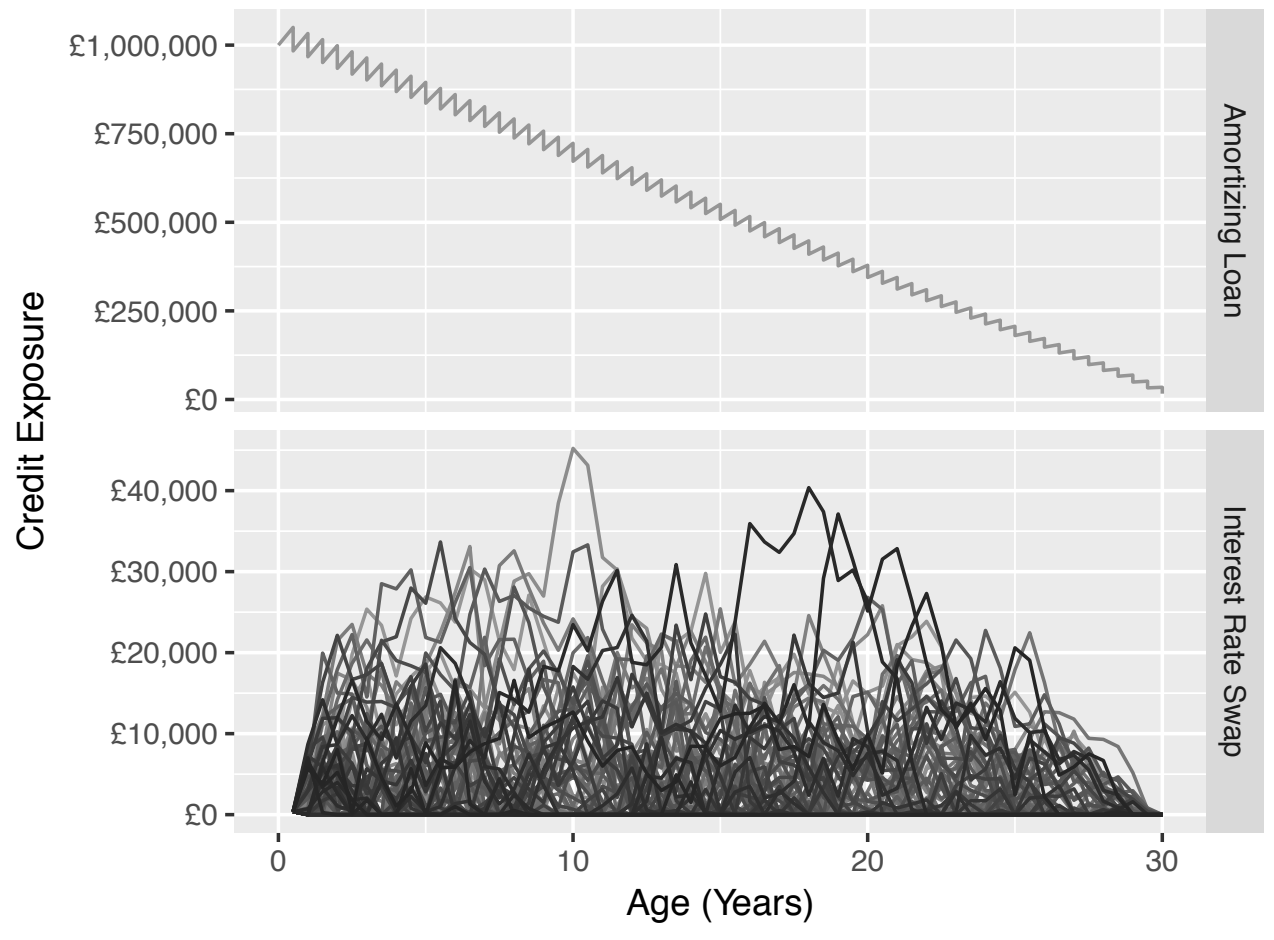

Figure 2: Simulated credit exposure of an amortizing loan and an interest rate swap. This figure was generated by simulating future interest rates using a one-factor Vasicek term structure model calibrated to historical data on changes in the value of US Treasury bonds. 